\title{
ENTOMOLOGICAL RESEARCH IN BRITISH WEST AFRICA.
}

\section{GAMBIA.}

\author{
By Jas. J. Simpson, M.A., D.Sc. \\ (with a Map showing the distribution of Glossina and Sleeping Sickness, and \\ 13 photographs by the author.)
}

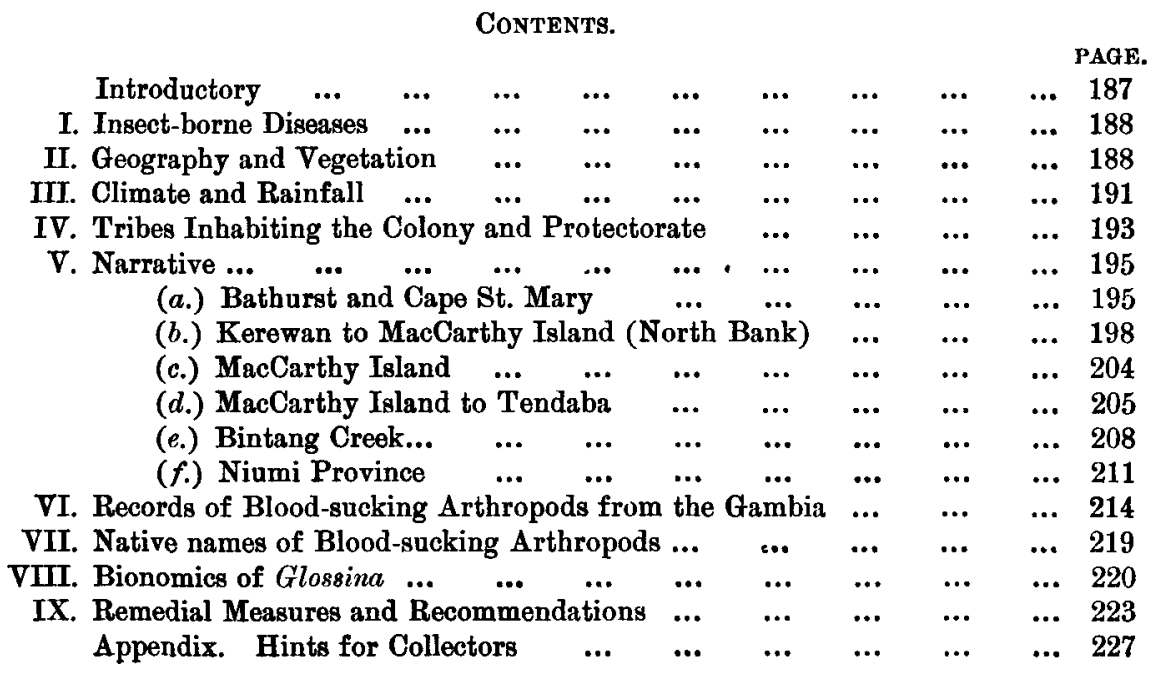

\section{INTRODUCTORY.}

In this short report it is proposed to deal exclusively with the blood-sucking insects and other Arthropods which are, or may be, implicated in the transmission of disease in man and animals. In this connection, however, certain aspects, geographical and geological, are necessarily involved, but these will be introduced only when considered to be directly relevant to the main issue.

Our knowledge of this subject, in regard to all West African British Possessions, is very meagre, but perhaps not more so in any than in the Gambia. Prior to the Expedition of the Liverpool School of Tropical Medicine in 1902-3, conducted by Drs. Dutton and Todd, little or nothing was known, and since that time only a few isolated records and observations, which will be referred to later, have come to hand. Several factors exist which may account for this state of things, but the most obvious is that only a few of the officials are compelled to leave Bathurst in discharge of their duty. Perhaps still more important is the fact that those who are interested in such work, and whose observations would be of great value, do not possess the small amount of material necessary for the purpose. Again the question of technique and the identification of material collected have always raised difficulties, but these are now reduced to a minimum, and it is hoped that this short Report, with its appended map, " may show how

* The villages in which human trypanosomiasis was diagnosed by the Expedition of the Liverpool School of Tropical Medicine in 1911 have been indicated on the map so as to make it more complete. For fuller details of these see Ann. Trop. Med. and Paras. Series T. M. Vol. V. No. 2, pp. 245-286. 
little has been done, and thus stimulate others to add their quota so as to bring the Gambia into line with other parts of the world.

An appendix has been added emphasising the chief points to be observed in collecting and preserving insects for identification, and indicating the method by which such collections will be identified, acknowledged, and incorporated with previous work.

\section{Insectr-Borne Diseases.}

Before we proceed to the purely entomological part, it might be well to draw attention to some of the factors which necessitate such work being carried out, and, in this connection, the occurrence and prevalence of insect-borne diseases command primary consideration.

(a.) Malaria, as in all the other West African Colonies, is almost universally distributed, and is by far the commonest insect-borne disease of the Gambia.

(b.) Yellow Fever is far from infrequent, however, and in May of this year four Europeans in Bathurst succumbed to it. In 1904 the late Dr. Dutton pointed out that Stegomyia fasciata was the mosquito most frequently met with in Bathurst, but this is not now the case, though, even in the dry season, numbers of this species are always present. At the end of April, while stationed in the Military Barracks at Bathurst, I caught several $S$. fasciata in that building, and it is noteworthy in this connection that two of the four Europeans who died of yellow fever were quartered in an adjoining building within the same enclosure.

(c.) Sleeping Sickness is endemic in the Gambia. In 1901-2, two Europeans and six natives were found to be suffering from this disease and since then one other European contracted it in the Colony. In the spring of this year, Drs. Todd and Wolbach made an investigation of the sleeping sickness in the Gambia, and, after an examination of a very large number of natives, concluded that about 0.8 per cent. are probably affected with Trypanosoma gambiense. This is a fairly high percentage, and although there never have been regular epidemics, and the natives may have acquired some sort of immunity or resisting power, still the question of transmission to Europeans is too serious a factor to be lightly passed over.

(d.) Animal Trypanosomiasis is also very prevalent; a large percentage of the cattle are infected, and the rate of mortality amongst horses is high.

With these facts kept well in view, the importance of a fuller knowledge of the various species of blood-sucking flies, their distribution, habits, and lifehistory must take a high place in any economic consideration of the Colony.

\section{Geography and Vegetation.}

The Colony and Protectorate of the Gambia is the most westerly and, at the same time, the most northerly of our West African possessions, being approximately in the same latitude as the north of Northern Nigeria. Its extreme limits north and south are approximately $13^{\circ} 48^{\prime} \mathrm{N}$., and $13^{\circ} 4^{\prime} \mathrm{N}$., while $13^{\circ} 46^{\prime} \mathrm{W}$, and $16^{\circ} 50^{\prime} \mathrm{W}$. may be taken as its eastern and western limits. It is a long narrow strip of country on the banks of the river from which it takes its name, and lies practically east and west. At no part is it more than 30 miles wide, while in some places it is only 15. Its total area is roughly about 5,000 square miles. 
The River Gambia rises near the source of the River Senegal on the northeast slope of the Footah-Jallon Mountains, to the north of Sierra Leone, and little more than 200 miles from the sea-coast. It flows first in a northerly direction and then west, entering British territory in, roughly, $13^{\circ} 46^{\prime} \mathrm{W}$. For a short distance it forms the boundary of the French and British spheres of influence, but after the village of Bananko both banks are in British territory. It enters the sea about 100 miles south of Cape Verde, the most westerly point of Africa. The river is an important water-way, but though navigable for ocean-going steamers for about 250 miles from the sea, does not lead beyond the coast region.

At Barraconda, 257 miles from Bathurst, there are falls or rapids, which make navigation even in the wet season difficult for any but very small steamers. Ocean-going steamers can, however, reach MacCarthy Island, 153 miles from Bathurst, at all times of the year. This is very important, inasmuch as European crews spend considerable time alongside the various wharves, subjected to all the influences of a tropical climate, and more often than not, without the usual precautions.

The river is 27 miles wide at its mouth, but opposite Bathurst, 18 miles up, it is only $2 \frac{1}{2}$ miles wide; it then gradually narrows, until near MacCarthy Island it is less than half a mile in width. No tributaries of any size pour their waters into the Gambia in British territory, and although numerous creeks of various sizes penetrate inland, they may be considered more as backwaters and overflows than as actual tributaries; they generally end in swamps, which are firm ground in the dry season, and which are used by the natives for rice farms. This must be borne in mind in connection with much of what follows and is of great importance in the question of tsetse distribution. The largest of these creeks is the Bintang Bolon (creek), which will be considered in greater detail later on. (See figs. 10 and 11.) The country through which the river flows is open, as compared with the forest belt of West Africa, which commences some 60 or 70 miles further down the coast, and extends to Accra on the Gold Coast. The valley of the river from MacCarthy Island to the end of British territory is hemmed in by low rocky hills of volcanic formation from 50 to 100 feet high, while the character of the surrounding country is park-like.

A study of the vegetation on the river banks necessarily involves a consideration of the nature of the water at various points, and this also in both the wet and the dry seasons. Towards the end of the wet season (i.e., October, November) the water is fresh down to the Suarra-Kunda creek, but in the dry season the fresh water recedes to a point a few miles east of Ballangar. From this point to Elephant Island the water is brackish, while below this the full influence of the sea is marked. The banks of the river, from its mouth to Ballangar, are fringed with mangrove swamp, behind which are plains densely covered with coarse grass, growing to a height of ten feet or over, and interspersed with thin bush and clumps of timber. The district between Ballangar and Barijali forms a transition stage in which there are mangroves in front, and trees, shrubs, palms, ferns, pandani, etc., in the background, the former diminishing, the latter increasing in number and extent the higher one ascends. Onwards from Barijali no mangroves are seen, and different parts of the bank show a varying preponderance of scrub, palms, etc., mentioned above (fig. 8). 
It is thus seen that the mangrove area corresponds, at any rate in the Gambia, with the extent to which the tidal influence is felt in the dry season. The nature of the vegetation behind the bank-fringe varies but little in the whole course of the river, except perhaps in the Niumi Province (the most westerly on the North bank), where there is a dense forest of small trees of no great extent.

The river is studded, especially in its middle portion, with islands of various sizes. The chief of these are :-Fort James, Elephant, Pappa, Pasul, Pasali, $\mathrm{Ba}$ - Faraba, Baboon, Kai-ai and MacCarthy Islands. None of these, however, are inhabited, except MacCarthy Island, which will be referred to later. With the exception of Fort James Island, which is merely a large rock in the middle of the river, and which was formerly used as a fortress, they are all densely covered with vegetation which partakes of the character of that on the corresponding part of the river banks, and are literally swarming with flies, which make a fierce attack on the occupants of passing craft.

Having thus considered the types of vegetation which fringe the river banks, let us now proceed to an analysis of the different plant associations in what may be termed the interior. Only in one part, namely, the Niumi Province in the north-west, is there anything approaching a tropical forest. This consists of trees of vastly different sizes, with a dense undergrowth of small scrub, bound together by epiphytes of various kinds. In places, however, and especially towards the edge, the large trees disappear and are replaced by smaller forms of a more uniform size, while the ground is covered with grass interspersed with a few small shrubs. Epiphytes are almost entirely absent.

Scattered throughout the whole Colony are fresh-water swamp forests of very limited extent; they occur generally in long belts and vary considerably in formation. Some contain very large trees scattered amongst others of a smaller size, while the ground is covered with a matted net-work of shrubs. Figure 1 shows a path cut through a belt of this type. In others the large

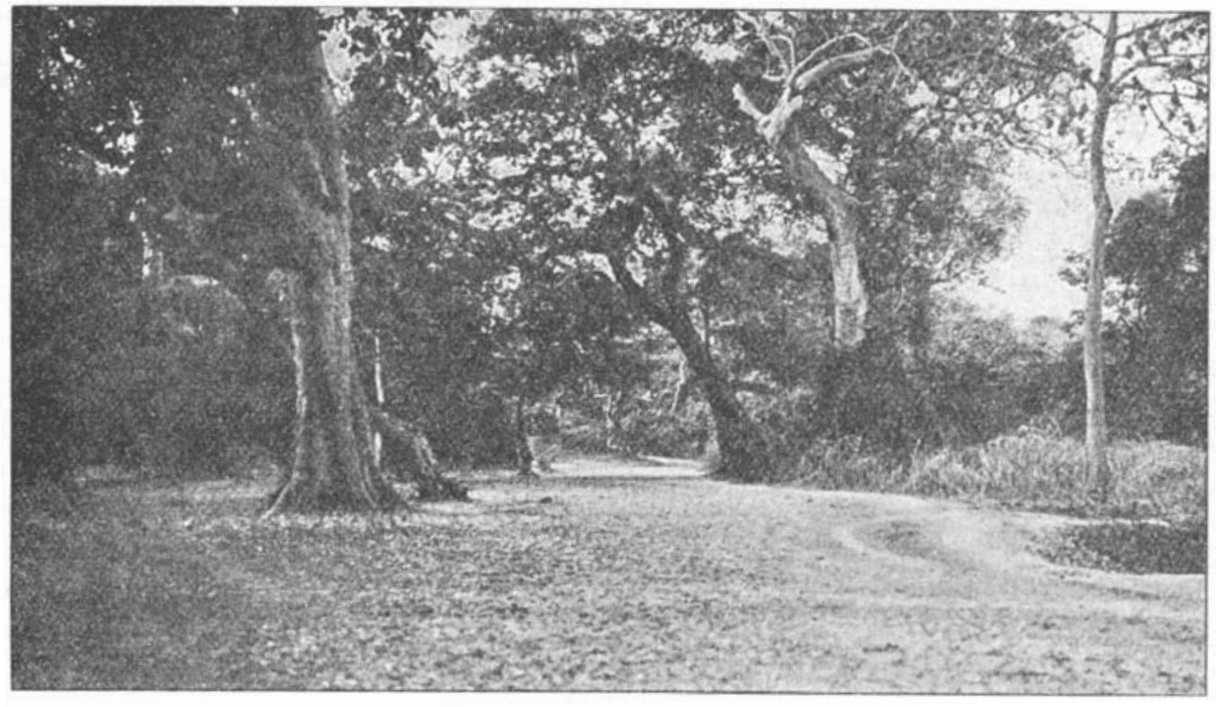

Fig. 1.-Path leading to well near Bakau Village. A fresh-water swamp forest in which $G$. palpalis are abundant. 
trees are replaced by evergreen shrubs and bushy trees. These furnish considerable shade, though not so dense as in the previous type, and are always associated with a tangled undergrowth. Figure 2 is typical of this class, while

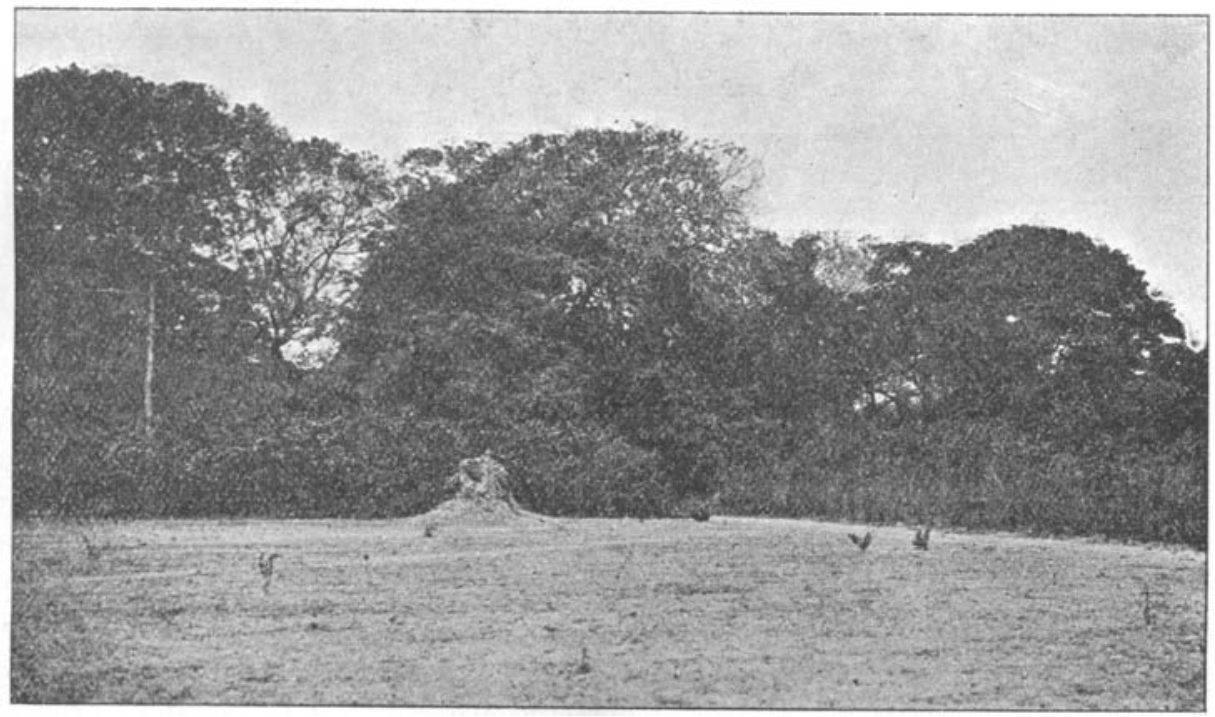

Fig. 2.-View near Bakau. Belt of evergreen shrubs and bushy trees with tangled undergrowth-a typical palpalis-haunt.

fig. 5 shows certain modifications, in which the proportions of trees, bush, and undergrowth vary, and where Oil and Borassus Palms make their appearance. The variation in the nature of these belts is due almost entirely to the amount of surface moisture, the greater the amount of moisture the denser the undergrowth.

Where laterite predominates, and where there is consequently a much greater desiccation during the dry season, there are extensive stretches of thin bush. In this type, the trees are small, more or less crowded, and present a stunted and gnarled appearance. They are all deciduous, and there is little if any undergrowth. Such small shrubs and grass as appear during the rains disappear soon after the middle of the dry season. In laterite outcrops, where the influence of the rains is hardly felt, large expanses of small bamboos of stunted appearance are met with.

A still more open type of country is seen in fig. 6 where there are practically no trees of any description and very little bush, but where grass predominates; this is associated with sandy soil and is the favourite site for villages and farms.

\section{Chimate and Rainfall.}

The year is clearly divided into two seasons, a wet and a dry. The wet season continues from June to September inclusive, while the other seven months constitute a period of drought. The rainy season begins and ends with tornadoes, which commence early in June, and the rains proper about the end of July. The maximum rainfall (between one-third and one-half of the total for the year), 
occurs during the month of August. The following Table A. gives the total rainfall at Bathurst for the past 10 years, and at MacCarthy Island for the years 1908-10, while Table $B$. shows the distribution for the various months both for Bathurst and MacCarthy Island during the years 1908-10.

TABLe A.

Rainfall in the Gambia.

\begin{tabular}{|cccc|c|c|}
\hline & & & & Bathurst. & MacCarthy Island. \\
\hline 1900 & $\ldots$ & $\ldots$ & $\ldots$ & $43 \cdot 38$ & - \\
\hline 1901 & $\ldots$ & $\ldots$ & $\ldots$ & $45 \cdot 31$ & - \\
\hline 1902 & $\ldots$ & $\ldots$ & $\ldots$ & $29 \cdot 42$ & - \\
\hline 1903 & $\ldots$ & $\ldots$ & $\ldots$ & $57 \cdot 13$ & - \\
\hline 1904 & $\ldots$ & $\ldots$ & $\ldots$ & $38 \cdot 02$ & - \\
\hline 1905 & $\ldots$ & $\ldots$ & $\ldots$ & $66 \cdot 07$ & - \\
\hline 1906 & $\ldots$ & $\ldots$ & $\ldots$ & $64 \cdot 36$ & - \\
\hline 1907 & $\ldots$ & $\ldots$ & $\ldots$ & $34 \cdot 00$ & - \\
\hline 1908 & $\ldots$ & $\ldots$ & $\ldots$ & $43 \cdot 54$ & $35 \cdot 89$ \\
\hline 1909 & $\ldots$ & $\ldots$ & $\ldots$ & $56 \cdot 59$ & $42 \cdot 03$ \\
\hline 1910 & $\ldots$ & $\ldots$ & $\ldots$ & $44 \cdot 00$ & $35 \cdot 40$ \\
\hline Average & $\ldots$ & $\ldots$ & $47 \cdot 44$ & $37 \cdot 77$ (for 3 years) \\
\hline
\end{tabular}

TABLE B.

Monthly Record of Rainfall in the Gambia.

\begin{tabular}{|c|c|c|c|c|c|c|c|}
\hline & & & 908. & & 909. & & 910. \\
\hline & & Bathurst. & MacCarthy. & Bathurst. & MacCarthy. & Bathurst. & MacCarthy. \\
\hline May & $\ldots$ & - & - & - & $0 \cdot 10$ & - & - \\
\hline June $\quad \ldots$ & $\ldots$ & 1.58 & $3 \cdot 25$ & $6 \cdot 13$ & $9 \cdot 68$ & $1 \cdot 15$ & $2 \cdot 88$ \\
\hline July $\quad \ldots$ & $\ldots$ & $9 \cdot 75$ & $7 \cdot 70$ & $8 \cdot 87$ & $10 \cdot 24$ & $11 \cdot 98$ & $9 \cdot 43$ \\
\hline August $\ldots$ & $\ldots$ & $24 \cdot 67$ & $13 \cdot 11$ & $19 \cdot 89$ & $12 \cdot 37$ & $16 \cdot 60$ & $10 \cdot 72$ \\
\hline September & $\cdots$ & $5 \cdot 35$ & $10 \cdot 35$ & $17 \cdot 30$ & 6.85 & $11 \cdot 52$ & $9 \cdot 86$ \\
\hline October ... & $\ldots$ & $2 \cdot 14$ & $1 \cdot 48$ & $4 \cdot 40$ & $2 \cdot 79$ & $2 \cdot 75$ & $2 \cdot 20$ \\
\hline November & $\ldots$ & - & - & - & - & - & 0.31 \\
\hline December & $\ldots$ & $0 \cdot 05$ & - & - & - & - & - \\
\hline Total & $\ldots$ & $43 \cdot 54$ & $35 \cdot 89$ & $56 \cdot 59$ & $42 \cdot 03$ & 44.00 & $35 \cdot 40$ \\
\hline
\end{tabular}


The most noteworthy feature in these tables is the enormous variation in the different years, e.g. 29.42 inches in 1902 as compared with 66.07 inches in 1905 . In $1908,24 \cdot 67$ inches, or more than half the amount for the year, fell during the month of August. The rainfall at MacCarthy Island is never so great as that at Bathurst.

The dry season, from November to May, is the season of excessive heat and cold; the highest maximum recorded for Bathurst was $104^{\circ}$ in May 1904 and 1906, while the lowest minimum was $46^{\circ}$ in December 1900 . The Harmattan, a north-east wind blowing from the Sahara, cold at night, and extremely hot and dry by day, blows intermittently from December to April. The range of temperature within 24 hours during this season is enormous, amounting sometimes to $30^{\circ}$ at Bathurst and $59^{\circ}$ up-country, but, in the latter district, $40^{\circ}$ is not uncommon. The excessive dryness of the air during the dry season may be gauged by the fact that at Bathurst there is sometimes a difference of $22^{\circ}$ between the wet- and dry-bulb thermometers, while up-country it is often greater. The mean temperature for the year at Bathurst is, however, not exceedingly high, ranging between $75^{\circ}$ and $85^{\circ}$, owing to the cool sea-breeze from the Atlantic, but upcountry, beyond reach of the sea-breeze, it is usually about $20^{\circ}$ higher than at Bathurst.

\section{The Tribes inhabiting the Colony and Protectorate.}

According to the Census of 1901, the total population of the Colony and Protectorate was slightly over 90,000 , but it is more than probable that this figure was considerably under the actual population. 'The details of the Census of 1911 are not yet available.

The natives of the Gambia belong to four distinct tribes: Mandingoes, Foulahs, Joloffs and Jolahs. Although there are a few professional fishermen at Bathurst and a certain amount of desultory fishing is carried on up-river, no tribe is to any extent dependent on the river for food. The country is essentially suitable for farming and cattle-rearing, and all four tribes carry on both these industries, though in varying degrees. Permanency of occupation of villages and the degree of segregation varies with the different tribes. The principal agricultural export from the Gambia is ground nuts or monkey nuts (Arachis hypogaea), and of these some 35,000 to 40,000 tons are exported annually. Guinea corn, maize, millet, rice, cassava, etc., are extensively grown for local consumption. The villages are situated generally in the centre of the area being farmed, and this always ensures an extensive clearing surrounding them. As the nature of the vegetation fringing the banks of the river precludes the possibility of any large settlement being established in the vicinity of the river itself, habitations are not found actually on the river banks, except in a few isolated instances, where there are wharves or ferries. The importance of this is obvious, inasmuch as where there are extensive clearings there are few or no tsetse, and the chances of infection by trypanosomiasis are accordingly diminished.

The Mandingoes are by far the most numerous tribe and are to be found scattered over the whole Colony and Protectorate. They are an agricultural people and live in large, well-built and cleanly-kept villages. 'There are generally a few large trees in each village, but in very few cases does one see 
any low scrub. A feature worthy of mention is the nature of the wells. These are generally dug outside the village and are usually about 30 to 40 feet in depth. The top is raised above the level of the surrounding ground, and the mouth is formed of large tree trunks well bound together. The area surrounding them is cleared and kept unusually clean.

The Joloffs inhabit chiefly the northern bank of the river and extend into Senegal. They also are an agricultural people and live in large permanent villages. In most of their habits which have a bearing on this subject, they resemble the Mandingoes.

The Foulahs, on the other hand, are more a pastoral than an agricultural people; they are closely connected with the Fulani of Northern Nigeria and own large herds of cattle. They are a somewhat nomadic tribe and are found all over the colony, but mostly in the upper reaches of the river. They have no permanent towns but only temporary shelters, and shift from place to place according to the requirements of their cattle. In the wet season they recede from the river and return towards it in the dry season, when the grass is burnt up in the more remote parts. For this reason, their settlements are never so well built nor so cleanly kept as those of either the Mandingoes or Jollofs. They never keep their cattle long in the vicinity of the river, and thus the latter are less liable to attacks from tsetse, and the fact that the Foulahs recede during the rains accounts, to a great extent, for the enormous herds which one sees all over the Colony. Though they give no reason for it, nor seek any, they recognise that a prolonged stay near the river or creeks, is nearly always accompanied by a higher rate of mortality in their herds.

The Foulahs are divided into three sub-tribes: Teucolors, Loubis and the Foulahs proper. The Teucolors are strict Mahommedans, and their language differs slightly from the true Foulah, as may be seen in the words given on page 219 .

The Jolahs are a very primitive and low type of natives, who inhabit the district of Fogni and spread into the French territory to the Casamance River. They are very unapproachable, jealous of their rights, and extremely vindictive. They do not segregate themselves into villages, but live in small compounds scattered about, each containing a separate "family." They are chiefly an agricultural people.

In addition to the foregoing, several other factors must be taken into consideration in connection with the spread of disease in man and animals. The political boundaries of the Colony of the Gambia are purely arbitrary and very artificial, and the River Gambia being the only water exit to the coast for the greater portion of French Senegal, a large amount of produce from the surrounding country passes to the coast by this river. This entails considerable intercourse between the natives inhabiting the river area and those from the high lands beyond. There is, further, considerable dealing in cattle between the two peoples, and thus the possibility of infected cattle finding their way into the upper regions is a very likely one. But more significant, however, is the fact that there is a large migratory farming community in the Gambia. Year after year, large numbers of natives from French and Portuguese territory come over to British territory and farm large tracts of land, returning to their homes as 
soon as the produce, which consists chiefly of ground nuts, is disposed of. The possibility, therefore, of diseases being carried from or into adjoining countries is by no means remote.

\section{NARRATIVE.}

Having now considered the geographical position of the Colony, its general physical conditions and plant associations, the climate and rainfall, and the natives, let us deal in greater detail with the localities visited, and see to what extent each and all of these factors influence the existence and distribution of the various members of the group of insects under consideration.

The dotted line on the appended map shows the route traversed by the author.

It was my intention to proceed up one bank of the river, cross over to the other bank at the extreme limit of British territory, and work back to Bathurst. My stay in the Colony extended from February 18th to May 1st, the last two and a-half months of the dry season, the only season of the year when it is possible, for Europeans at least, to do any considerable touring. Consequently, owing to the short time at my disposal, my proposed journey was found to be impossible, and therefore only typical portions were visited; while in addition to these, through the kindness of His Excellency the Governor, I was enabled to examine in the Government steamer the whole river to MacCarthy Island and also the Bintang Creek-by no means the least valuable portion of the investigation.

\section{(a). Bathurst and Cape St. Mary.}

Bathurst is the capital and principal settlement of the Colony. It is the only town having permanent European residential quarters. It is situated on the extreme eastern end of the Island of St. Mary. This island has an area of about four and a half square miles, and is little more than a mixture of swamp and sandbank, inundated during the rainy season. Although much has been done to fill up the swamps and drain the whole area, much still remains to be done to make the town a model tropical settlement. Commercially, the position is good, but residentially it is far from satisfactory, in spite of untiring efforts on the part of the Senior Medical Officer and his staff. Mosquitos, including Stegomyia fasciata, are to be found in considerable numbers. This is due in great part to the surrounding marshes, but also to the confined nature of most of the residential quarters and the lack of access of free air to these on account of the lower parts being used, in nearly all cases, as stores, \&c. The close proximity of the stables to the residential quarters (in some cases they are part of the same building) is a fact much to be deprecated. Tsetse do not infest the town during the dry season, but, I am told, are not infrequent visitors during the rains.

An exhaustive report on the town, from an entomological aspect, has already been published by the late Dr. Dutton; and, from my short stay and examination, I do not feel justified in amending or adding to this excellent piece of work. $I$ understand that a scheme is on foot to remove the residential quarters from Bathurst to the vicinity of Cape St. Mary, and in view of the recent epidemic of yellow fever, when four Europeans died in one week, some such drastic measure is necessary. Cape St. Mary is situated about seven miles from 
Bathurst, and is separated from it by an island, but both creeks are bridged. The Cape itself is situated on the mainland, and has a northerly and westerly exposure to the full force of the cool, invigorating, Atlantic breeze. Even in the hot season, when work is carried on in Bathurst under adverse climatic conditions,

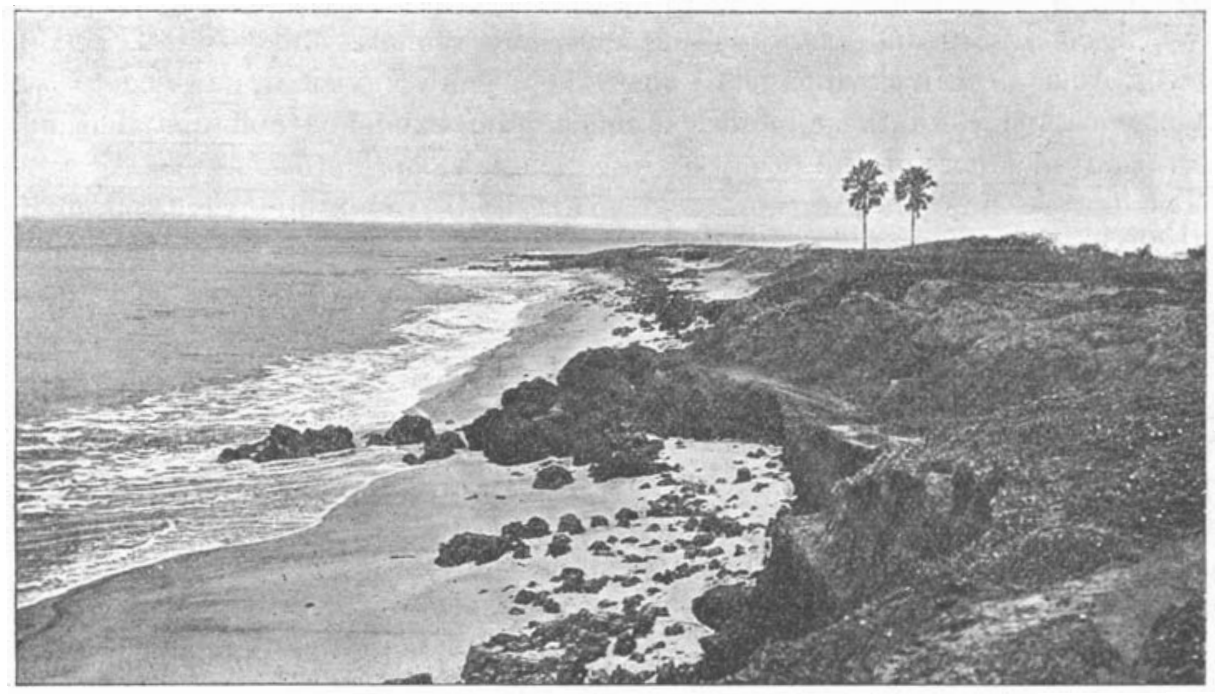

Fig. 3.-View of the coast bluff at Cape St. Mary.

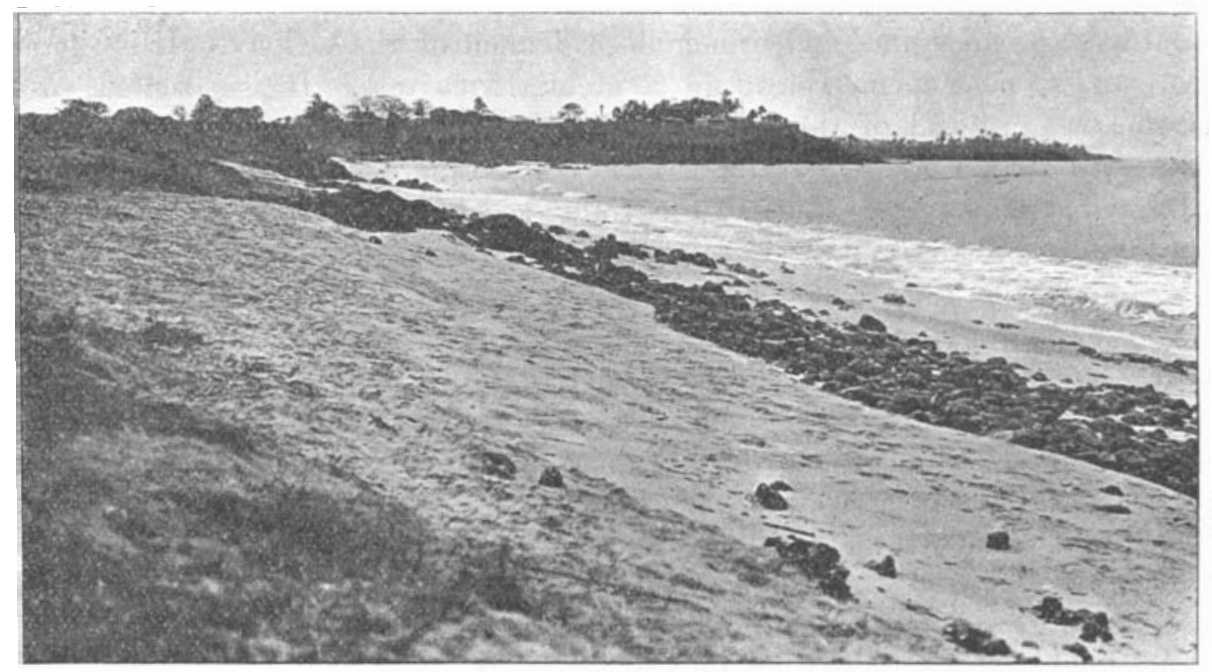

Fig. 4.- View of the beach at Cape St. Mary, showing Government House on a high rocky bluff.

there is a steady cool breeze at the Cape. For miles along the western aspect there is a high bluff some 50 or more feet above high-water. Near the Cape itself there stands a substantial Government House, built of stone and overlooking the sea, while several Bathurst merchants and others have built private houses there, which they use as week-end health resorts. 
At the request of Dr. Hood, the Senior Medical Officer for the Colony, I visited and examined this whole area as a possible site for a sleeping-sickness camp. When in the Colony, I submitted to him a short report, but the following notes summarise the most important features, while the actual question of a sleeping-sickness camp will be referred to later. Near the Cape itself there is a small town, Waslunga, which is very close to an extensive mangrove swamp, and here Glossina palpalis was caught. This village ought certainly to be removed further from the swamp, chiefly because of the continual intercourse that exists between it and Bathurst.

Bakau is a small village near Government House, and is one of the few exceptions found in the Colony where the village well is enclosed by dense thick bush (fig. 1). This village, and the surrounding bush, is a haunt of all forms of noxious insects. In the enclosure of the European house in which I was quartered when at Bakau, the following flies were caught:-Glossina palpalis, Stomoxys calcitrans, Lyperosia minuta, and Haematopota decora; while one small species of Tabanus was also seen. From my pony I obtained the following ticks:-Amblyomma variegatum and Hyalomma aegyptium. Extensive clearing around this village is strongly to be recommended; it will not be necessary to cut down the large treeg, but only the thick undergrowth to a height of about 10 feet, so that the sun's rays may have full access to the soil. Glossina palpalis was also caught at the following places:-the bridge crossing Oyster Creek, Camelo Bridge, two places between Jesswang and Taranakunda, Bakotti Bridge, Newcastle, and the bridge near Jesswang (see Map). Although there is extensive clearing in this whole region, large clusters of bush, with consequent stagnant water or surface moisture, have been left, and these are all harbours and centres of distribution for tsetse (figs. 2 and 5). The whole of this region is very flat

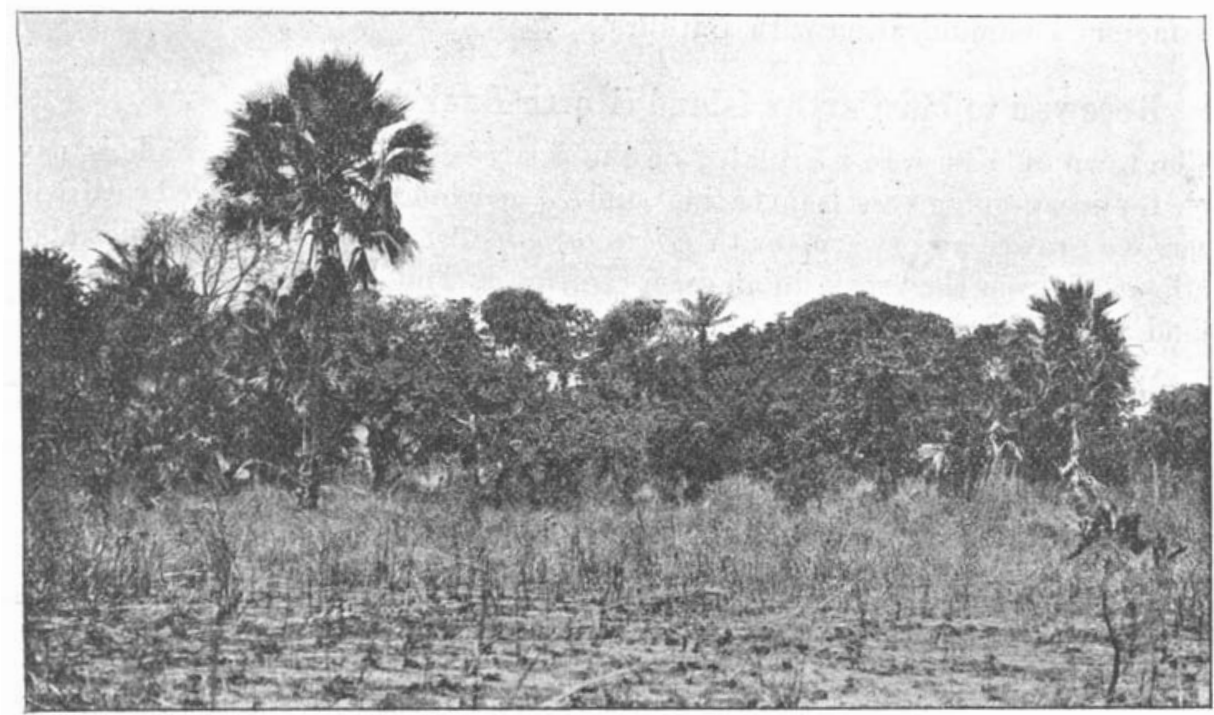

Fig. 5. - View near Bakau showing open forest belt with Oil and Borassus palms. 
and fertile (fig. 6), and consequently there are numerous villages; yet in spite of the frequency of Glossina palpalis at present, it is not too much to say that, with some judicious clearing such as that recommended for Bakau, the whole arca could be very easily freed from this pest. No tsetse occur, so far as I

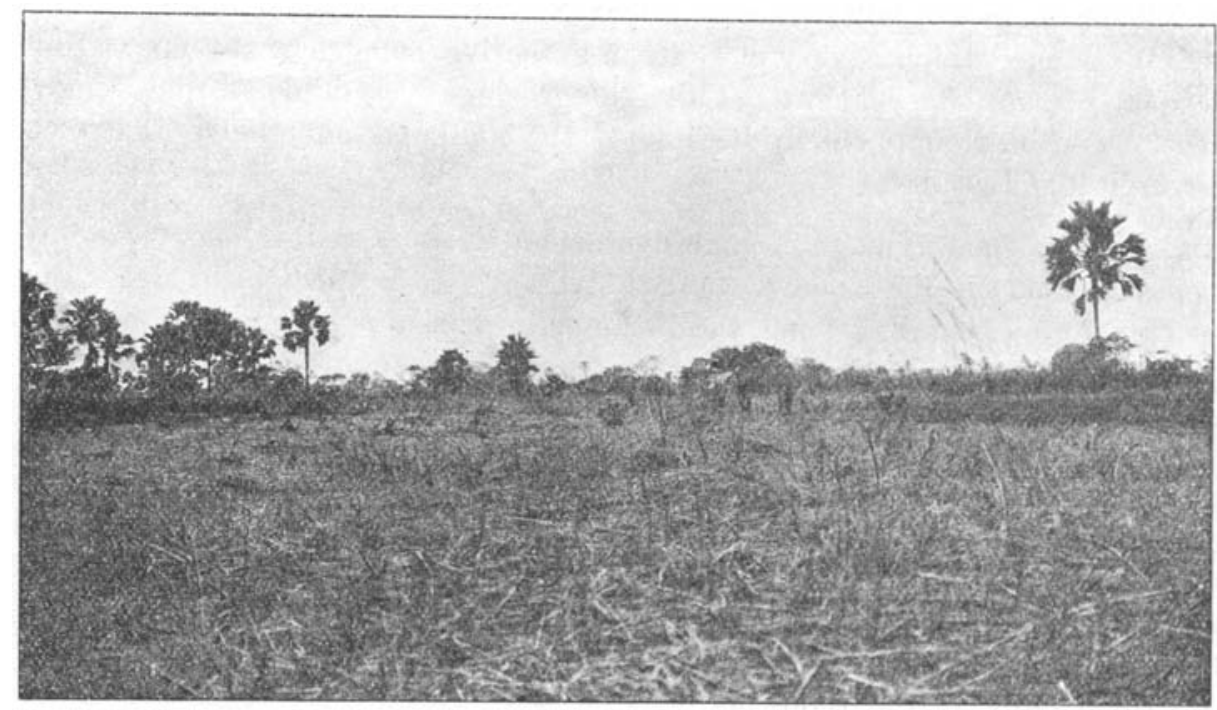

Fig. 6.-View at Cape St. Mary, to show the open nature of the surrounding country.

could ascertain, in the vicinity of the coast bluff, where it is proposed to build the new European quarters, and without interfering with the Rifle Range which exists there at present, adequate accommodation is available for a sleepingsickness camp without in any way jeopardising the military occupation, or affecting satisfactory cornmunication with Bathurst.

\section{(b.) Kerewan to MacCarthy Island (North Bank).}

The town of Kerewan is situated on the Suarra-Kunda Creek, which is navigable for ocean-going vessels up to this point. The whole creek is fringed with dense mangrove growth and swarms with Glossina palpalis. The town itself lies about a mile away from the creek, in an open clearing. The country for several miles around is completely denuded of bush and is extensively cultivated. On my visit here, a large Norwegian steamer was loading ground nuts at the Kerewan Wharf. The captain informed me that although he had been there for four days, he had not seen a single mosquito; but on the other band, tsetse were very troublesome, invading even the saloon below. Practically no clearing had been done in constructing the wharf ; in fact, both bow and stern of the vessel were stuck fast in the mangrove thicket.

From Kerewan the main north-bank road diverges from the river and passes through Saba, Salikeni, Nja-Kunda, No-Kunda to Illiassa. The whole of this area is extensively cleared for cultivation, the ground is sandy, and the surrounding country is open and park-like in character, and in no way suited for 
tsetse haunts. Near No-Kunda there is a small area of thick, low scrub, but the town itself stands in an open clearing, while between No-Kunda and Illiassa there is a long swamp which, at the time of my visit (March 10th), was practically dry, except in one place where the crossing is muddy and the water about two feet deep. This swamp is an extension of two creeks, the Katchang Bolon and the Tunku Bolon. During the wet season, the overflow of the river would cover an area of considerable extent, and it is worthy of note that Glossina palpalis was afterwards caught at the mouth of the Katchang Bolon, so that it is more than probable that the range of this insect would extend in the wet season practically up to Illiassa. None were seen, however, on March 10th, when a strong Harmattan was blowing.

At all the towns mentioned there were large herds of cattle, numerous goats, and not a few donkeys. Conversation with the headmen of the towns failed to elicit much reliable information either with regard to biting flies, sleepingsickness, or diseases of cattle, but an attempt was made to find out the native names of the various blood-sucking insects. Some consideration of this will, however, be given in detail later. Elephantiasis is very prevalent in nearly all these towns.

Beyond Illiassa, the character of the vegetation changes somewhat. The first part of the way is the main road to Kubendar and is well cleared, but near Yalloll the road branches off to Farafeni and consists simply of a bush-path, first through thin low scrub and later through thin bush. Between the two Foulah towns of Yalloll and Fula Farafeni, the bush is thin and stunted, consisting of deciduous trees with little undergrowth, and is a haunt of Glossina morsitans (fig. 7). Wherever there are Foulah towns, there one sees large herds of cattle, but little cultivation and consequently little clearing. The head-man of Farafeni

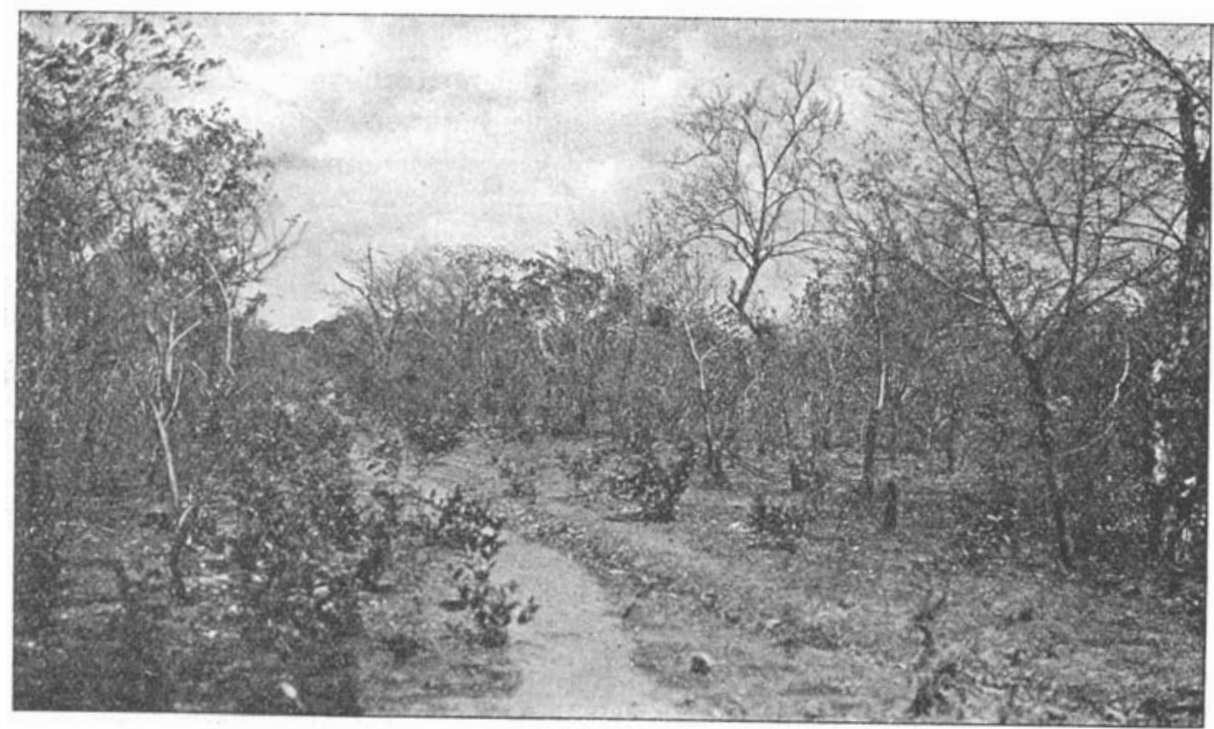

Fig. 7.-Path through thin deciduous bush between Yalloll and Fula Farafeni to show a typical morsitans-haunt. 
complained most bitterly of a great loss of cattle during the past two years, and his description of the disease was extremely suggestive of trypanosomiasis. When questioned about tsetse, he denied their occurrence actually in Farafeni, but stated that they were to be found at Beretto towards the end of the rains, which is not at all improbable.

The road from Farafeni to Ballangar passes through Sukotto, Kattaba, Dipakunda, M'Palen, and N'Geyen Sanjal. Between Kattaba and Dipakunda several tsetses (? G. morsitans) alighted on my pony's neck. The bush in this part is exactly the same as that between Yalloll and Fula Farafeni. In the camp at Dipakunda, a tsetse, almost certainly G. morsitans, settled on my arm, but unfortunately I did not manage to secure it. Tabanus taeniola also exists here, and one $T$. ditaeniatus was seen; one flea (Ctenocephalus felis) was obtained.

Between Dipakunda and Ballangar lies N'Geyen Sanjal. The road runs through thin bush and over two iron-stone ridges. About a mile from N'Geyen Sanjal there is a gully, which obviously contains water. in the wet season, while about three miles further on there is, surrounded by a laterite ridge, a swamp (dry when visited on March 13th), which must also be covered with water during the rains. At Ballangar a specimen of Tabanus ditaeniatus was caught on the pony at noon, and at 6 p.m. a tsetse, almost certainly Glossina morsitans, alighted on the writer's leg in camp. The Ballangar wharf is about three miles from the native town and is connected with it by thin bush; it is a very important loading place for ground nuts, and several European merchants are stationed here in the dry season. The clearing is quite inadequate and Glossina palpalis is frequently met with. From Ballangar wharf to Kauur, the country was one large dry swamp, which must be practically impassable in the rainy season. In the dry season the mud is baked hard and cracked, and consequently one would not expect to find tsetse at this season of the year, but, in the wet season, it is extremely probable that $G$. palpalis is to be found the whole way between the two wharves. Kauur wharf lies about two miles from the native town; there is little or no clearing, and the jetties are simply built out into the river and are fringed on both sides by mangroves. I took the opportunity of going out on the river in a rowing boat, but although several $G$. palpalis and $T$. taeniola were flying around, I was unable to secure specimens. One of the French traders here told me that tsetse were very troublesome when the natives were loading, and that they even invaded the European houses nearly half a mile from the river bank.

Leaving Kauur, the road passes through thin bush the whole way to N'Jau. Not far from N'Jau is the small town of Bulghurk, and here one Glossina morsitans was seen on the pony's neck. From Bulghurk to N'Jau, the road runs practically along the French boundary. At N'Jau Tabanus taeniola was caught on the pony's neck at 4.30 p.m., while at 6.15 p.m. Glossina morsitans was captured biting the writer's arm in camp.

Between N'Jau and Tento there are a number of small villages, notably Leba, Amodi, Panchang, and Porli. Leba is about $1 \frac{1}{2}$ miles from the Nianija Bolon, one of the largest creeks on the north bank of the River Gambia. From Leba to Tento, the road runs nearly parallel with the creek at distances varying from $1 \frac{1}{2}$ to 2 miles from it, while immediately after Panchang a small dry water course 
is crossed. Particularly to be noticed on this day's march was the large number of Borassus palms, which so far had hardly figured in the vegetation. Tsetse were seen at Amodi, Panchang, and Porli, and all seemed to be Glossina morsitans, although, from the nature of the country and the close proximity to the creek, one would rather expect to find Glossina palpalis. One specimen caught on the pony at Panchang at 8.15 a.m. was $G$. morsitans, as also were others caught at Tento in the stable at $12.30 \mathrm{p.m}$. so that in all probability the others were also morsitans. Tabanus taeniola was also caught in the stable at 11.30 a.m.

Between Tento and Ker Sidi there was a dried up swamp, and across this I rode with the Commissioner at 5.30 one evening. Although we had to walk our horses across the swamp owing to the broken nature of the surface, no biting flies of any kind were to be seen. It was two days after full moon (March 24th), and when I was riding back between 9.30 and 10 p.m. the pony showed signs of irritation, became restive and kept swishing his tail about vigorously. As we had had a very bad encounter with a swarm of bees a few days previously, and, as there was a distinct buzzing sound, I became apprehensive. The buzzing increased, and numerous flies made repeated darts at my head, neck, and hands; I managed to secure two of these gorged with blood. The pony, by this time, was well-nigh uncontrollable and $I$ made for camp. On examination the two flies proved to be Glossina morsitans. There could not have been fewer than 100 of them, and their persistence of attack, and the buzzing sound emitted, were more suggestive of Hymenoptera than tsetse.

Immediately after leaving Tento, the road runs parallel with the Nianija Bolon at a distance of less than 100 yards from it. The whole way to Niani Bantang, where the creek is crossed by a "crinking" (interwoven strips of bamboo) bridge, the country is fairly open and extensively cultivated, but the banks of the creek are covered with dense bush and high shady trees. There were a few dry places, but the greater part of the Bolon still retained water. I halted for a time at the Nianga crossing, but on or around the pony (which generally acts as a tsetse decoy) only Stomoxys nigra was found, apart from other non-bloodsucking Diptera, which are irritating to horses and cattle, and very annoying to man.

From Niani Bantang to Jalo Kunda the road passes through open thin bush. The headman of Niani Bantang informed me that both tsetse and large Tabanids swarm there during the rains, but in the dry season are extremely rare. From Jalo Kunda to Gassan, the road is through thin bush and bamboo, the latter predominating where there is a preponderance of laterite and little or no telluric moisture. The camp at Gassan is close to a swamp, and a species of Anopheline, Nyssorhynchus pharoensis, was caught in one of the houses at 10 a.m. ; this was the first mosquito seen since leaving Bathurst.

The town of Gassan being close to the river, I took the opportunity of examining a portion of the latter to see to what extent anyone, rowing close to the river bank, would be subject to attack by tsetse. For this purpose, I got a native canoe, or dug-out, and proceeded to Wassu, a small wharf about three miles further up the river, always keeping within 50 yards of the bank. The 
vegetation on the river bank was very dense and overhung the water. It consisted chiefly of palms, pandani, ferns, and thick bushy shrubs (fig. 8). No

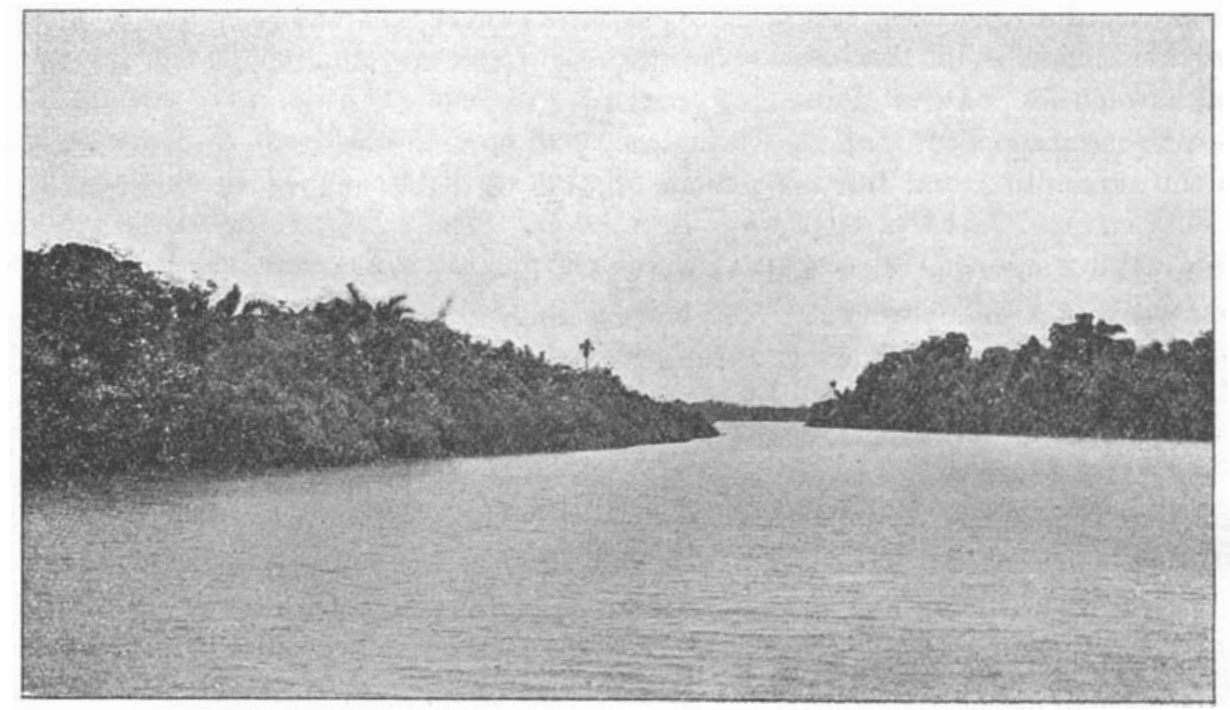

Fig. 8.-View on the River Gambia beyond Barijali showing the dense nature of the vegetation which consists of Ferns, Palms, Pandani, \&c., and is a typical palpalislocality.

sooner had we pushed off from the bank than numbers of biting flies assailed us. The following TABANIDAE kept hovering round, Tabanus secedens, $T$. fasciatus and $T$. taeniola, but as movement is very restricted in this type of canoe, none were actually caught. It was different, however, in the case of tsetse; these simply swarmed round and attacked persistenily. After a number of specimens were secured, no further attempt at capture was made, and it was with difficulty that we managed to guard against too many bites. A ground-nut steamer was being loaded at Wassu, and here tsetse occurred in such numbers and so persistently darted from one person to another that a distinct humming sound was to be heard. After a very short stay, we pushed off and were followed by a large number of these insects, but by the time we had reached 70 to 80 yards from the bank, all had disappeared. On returning to camp at 1.30 p.m. we caught one Stomoxys nigra and one tsetse in the stable.

The opposite bank of the river bore very little in the way of regetation; clusters of ferns and a few palms were scattered about. At 2 p.m., we crossed over to this side and moved slowly up-river to opposite Wassu, again keeping within 50 yards of the bank the whole way. The.only Tabanid caught was Tabanus taeniola, but tsetses were quite as troublesome as on the other bank; two were caught in coitu at 3.30 p.m. and must have flown from the bank, some 50 yards, in this attitude, as they were thus seen approaching the canoe some yards off.

The identification of the tsetses, secured on these two canoe trips, was a matter of some difficulty. It was well-nigh impossible to assign them to any definite species on the basis of external characters alone. In some respects they resemble $G$, tachinoides, e.g. in their small size and in the extent of the pale markings on 
the abdomen, but the dark bands are not so sharply defined as in this species nor is the quadrilateral area on the first segment so definitely marked. Professor Newstead* has very recently made a study of the male genital armature of the various species of Glossina. In his paper, page 23, he points out that the form of the inferior claspers distinguishes the two species, palpalis and tachinoides. Dissection of two of my specimens showed that the inferior claspers corresponded with the form described by Newstead for G.palpalis, and on the assumption that this is a specific character, I determined to relegate them to that species. At the same time, it must be borne in mind that they are far from typical palpalis as regards their external markings, and apart from the question of a local race they almost justify the establishment of a new variety.

The road from Gassan to Kantaur lies through thin bush. Around Kantaur, which is a fairly large town, there is extensive cultivation and consequently a large amount of clearing. Shortly after leaving Kantaur, the road passes over a high rocky laterite plateau, covered with clusters of stunted bamboo growth. The descent to Manna is very steep and rocky. No blood-sucking insects of any description were seen on this trek, nor does the type of country seem in any way adapted for them.

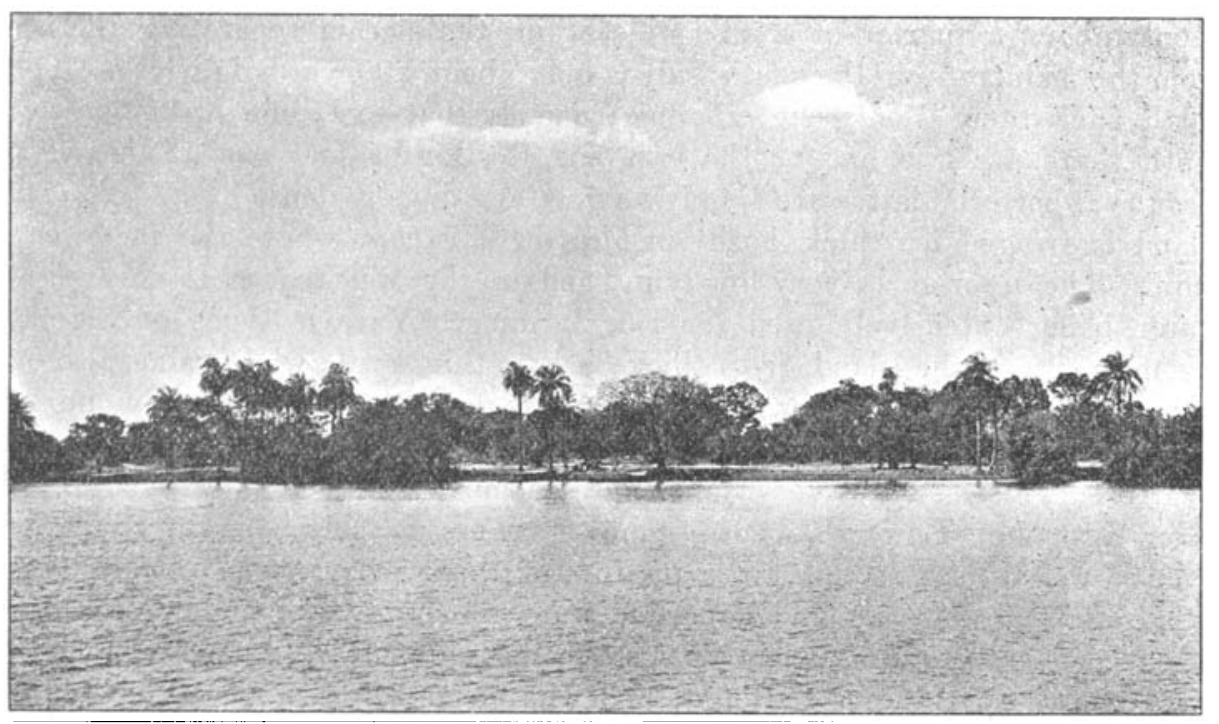

Fig. 9.-Beach at Lamin Koto, opposite MacCarthy Island.

The time at my disposal being short, I found that it would be impossible for me to continue onwards on the north bank, so I thought it advisable to cross over to MacCarthy Island and work towards Bathurst on the south bank, especially as the Government steamer does not proceed further up-river during the dry season. For this purpose I pushed on to Lamin Koto, the north-bank ferry for MacCarthy Island. As the formation of the bank at Lamin Koto is very typical of many wharves on the upper river, I have given a photograph of it (fig. 9), and a short description may be useful and suggestive. The soil, for

- Bulletin of Entomological Research. Vol, II. Part I. pp. 9 to 36. 
a considerable distance from the river, consists of thick mud, which, in the dry season, is baked hard and much cracked. Numerous large trees and a small amount of bushy scrub occur in the vicinity of the river, and there are also a few scattered Oil-palms. At the actual crossing, a certain amount of clearing has been done, but this is by no means adequate, inasmuch as sufficient bush has been left to form an admirable tsetse refuge. This applies to nearly all the ferries on the river. At almost any hour of the day, numbers of natives with goats, sheep, donkeys, cattle, etc., may be seen waiting for canoes to ferry them across, and all these are subject to tsetse attacks.

The camp at Lamin Koto is situated about a quarter of a mile away from the river bank, but during the wet season this whole area is inundated with water and it is possible to row close up to the camp. The importance of this will be seen later in a discussion on the possible breeding-grounds of $G$. palpalis.

\section{(c.) MacCarthy Island.}

MacCarthy Island lies about 150 miles from Bathurst; it is, roughly, 6 miles long and $1 \frac{1}{2}$ miles at the widest part, near the middle; from this it tapers to both ends. The main branch of the river is on the north side, and even here it is only about a quarter of a mile wide, while the stream separating the island from the mainland on the south side is only about 200 yards in width. To the north bank there is only one crossing ; namely that to Lamin Koto, but to the south there are two, one at the east end to Boraba, and one at the west to Faraba ; both the latter are simply narrow clearings in dense bush. The whole island is fringed by thick bushy undergrowth, except where the factories are built. The interior is very low-lying, and in the wet season is covered with water, being extensively used for rice farming. Various types of vegetation are met with on the island, from thick bush to thin scrub, while palms also occur in places, but there are few trees of any great size. There is only one small native village, situated near the centre of the island, close to the European quarter. This island is very important, inasmuch as it separates the "Upper" river from the "Lower." Ocean-going steamers ascend the river to this point even in the dry season. All the produce of the upper river is brought down to this island in schooners and deposited until the large steamers call and take it direct to Europe ; consequently it is the most important commercial depôt in the colony, apart from Bathurst, and European representatives from all the trading firms are stationed here during the dry season. The Government steamer also calls weekly in the dry season, and fortnightly during the rains. There is a large Government House, used chiefly by travelling officers, and a native hospital and dispensary. Quite recently, a European hospital has been built, and a medical officer has since been stationed there. Between Government House and the Boraba crossing, Glossina palpalis was caught, while, in a canoe, at the crossing itself both $G$. palpalis and Tabanus taeniola were found. On my second visit to the island, while in the Government steamer, which was

* The Glossina caught at MacCarthy Island show the same markings as those described from Gassan and Wassu. 
lying about 100 yards from the wharf, I caught Glossina palpalis between 5 and 6 p.m.; also while we were passing the south end of the island in the steamer, at a distance of abont 50 yards from it, G. palpalis flew on board one morning about 8 a.m.

Auchmeromyia luteola, the adult of the floor maggot, was very common in Government House, and Pyretophorus costalis was also canght. Sleeping-sickness is not uncommon in MacCarthy Island, and this, added to the fact that there is a large European settlement here, makes it absolutely imperative that something should be done to effect at least a diminution in the number of lsetses in the island.

\section{(d.) MacCarthy Island to Tendaba.}

After crossing the river at the west ferry in canoes, we found the country very open the whole way to Faraba. Between Faraba and Patchari there is an extensive swamp which, even in March, retained water in some places. Rice is grown here only at the end of the rains. Patchari is a town of small size ; Borassus palms are a marked feature in the landscape. Parts of the road are rocky, and bamboos occur in considerable quantity. Three species of Tabanus, namely taeniola, laverani, and another, probably new, were caught round the village well, while water was being drawn for the cattle. Mosquitos (Culev decens) were very troublesome at night, but the reason for this was not far to seek. Rest-camps in the Gambia consist of a number of houses built cf "crinking," the local name for interwoven strips of bamboo, and thatched with grass, the whole surrounded by a fence of the former material. As these camps are not used during the wet season, it is not necessary to guard against rain ; consequently this open lattice work adds considerably both to light and ventilation, and therefore minimises the chance of mosquitos lurking about. At Patchari, however, the walls of the principal rest-house, in addition to having the usual crinking, are also covered with mud, making the house very much darker, and it is worthy of note that in all houses in which this method of construction has been adopted, mosquitos were found. Now, the chances of these insects breeding in the camp are very remote, as the only water in the camp is brought, on the arrival of the European, in pots belonging to the village, and these are most sedulously guarded, and removed immediately after the camp is vacated. It is more than probable, therefore, that the mosquitos invade the camp after they are hatched, and that the dark, moist places, caused by the mud walls, serve as a retreat. Although in this actual instance only Culicines were caught, still there is no reason why Anophelines might not also occur. Consequently it is inadvisable to use mud in the construction of houses, if it can be avoided. This feature was more noticeable at Brikama where 32 mosquitos, all Culex decens, were caught between 10 and 10.30 a.m. on my arrival in camp. Two of the houses in this canp were made of mud. One Tabanus, probably a new species and similar to that caught at Patchari, was obtained near the well.

From Brikama to Tenenfara (Madina) practically the whole road lies at the foot of a bamboo-covered, laterite ridge, which forms the eastern limit of an extensire swamp. Even at the end of March, there was a considerable amount 
of water in many places, and large water-fowl were abundant. There is an enormous number of rice farms in the drier parts of the swamp. The road is very sinuous, following the inequalities of the uncertain ridge. There can be no doubt that this is a pestilential part in the rains, and must be a hot-bed of Glossina and TABANIDAE (Mangrove flies)." Even at the time of my visit G. palpalis occurred in the camp, which is some considerable distance from the swamp, one being seen at 9.30 a.m., while others were found near the wateringplace throughout the day. Tabanus taeniola was seen in the stable at 4.30 p.m. From Tenenfara to Kudang the country is moderately open, and no biting flies were seen. The small number of flies of any sort was to a great extent accounted for by the excessive heat, the mid-day shade temperature during these days being $104^{\circ}$ to $105^{\circ} \mathrm{F}$. From Tenenfara to Kudang, the country is covered with thin open bush, and there is a large amount of cultivation; no biting flies were seen. The road from Kudang to Jarreng passes through Fula Kolon, Bamba Kolon, and Gauwa, and thus skirts the edge of an extensive swamp. At Jarreng one large Tabanus, similar to those got at Patcheri and Brikama, was caught. From Jarreng to the Sofaniama Bolon, there is simply a small track through thin bush; the creek itself contained very little water, while after that the road passed over a "baked" swamp, consisting of a number of rice fields. One Tabanus taeniola was caught flying round the horse in camp at Sukuta at 5.30 p.m. The route from Sukuta to Dassalami passes through a small part of French territory over a rocky laterite ridge. After leaving Dassalami, the end of a long creek, consisting of a large number of rice farms, is skirted. An examination of the bush in the vicinity of the creek failed to reveal any biting flies ; in fact, except for one Dipteron, nothing but a large number of honey-bees was seen.

Bureng to Jappeni. Practically the whole of the track from Bureng to Badumi (a small town not shown on the map, but lying about half-way between Jassong and Jappeni) skirts the fringe of an extensive swamp in which stagnant water occurs in several places ; large clusters of dense bush and Oil and Borassus palms are abundant at several places on the route. Glossina morsitans alighted on the pony's neck while I was at Badumi ; three were to be seen on him at one time while standing near the village well. Between Jassong and Badumi the country is such as might lead one to expect Glossina palpalis ; in fact, it is more than probable that it does occur here during the rains. From Badumi to Jappeni the road passes through thin bush, typical morsitans-country. Auchmeromyia luteola was obtained at Jappeni.

From Jappeni to Soma the road passes through two small towns, Buiba and Karantaba. Before reaching the town of Buiba the head of the Buiba Bolon is crossed; around this ridge there is dense bush and numerous oil palms. The approach on either side is a well shaded avenue, and here Glossina morsitans occurred in greater numbers than in any other part of the journey. Close to the town of Buiba there is a large open clearing, and on approaching it we saw an enormous number of dog-faced or Guinea baboons (Papio sphinx) of all sizes.

* As there seems to be a certain amount of misunderstanding in some quarters with regard to what are actually included in the term "Mangrove flies" I may take this opportunity of pointing out that this term is collective for TABANIDAE, large and small, and does not include such insects as Cordylobia anthropophaga, the maggot-fly, which does not bite. 
The road ran through the middle of this area, and on my arrival the baboons scattered to both sides. While passing over the ground recently occupied by them, the pony was badly attacked by tsetse, which had evidently followed the baboons to the open ground; many of them were gorged with blood and could fly only with difficulty. On three occasions during my tour in the Gambia, have I witnessed this phenomenon; namely, the predilection of Glossina morsitans for following a troop of baboons, even in the heat of the day, from their shady retreats into the open. At Buiba, the following blood-sucking flies were captured :-Glossina morsitans, Tabanus taeniola, and Tabanus ditaeniatus, all around the pony between 10 a.m. and 12 noon.

At Soma, Glossina morsitans, Tabanus taeniola and $T$. par were caught between 3 and 4 p.m. The road from Soma to Kaiaff lies through open bush, but there are two swamps containing large pools of stagnant water; these are fringed with dense bush and seemed likely places for Glossina palpalis. None, however, were seen, but $G$. morsitans occurs all along the route.

I spent a day at Kaiaff and examined the whole of this vicinity. Near the swamps, there are numerous rice farms surrounded by thin bush and scanty undergrowth, and here $G$. morsitans exists in considerable numbers. Other blood-sucking flies caught at Kaiaff were :-Tabanus taeniola, Tabanus ditaeniatus and Tabanus par, all very abundant in the stables. Between Kaiaff and Mandina, the country is open and almost completely cultivated the whole way. At Generi, a small town about 3 miles from Kaiaff, Glossina morsitans was caught, but at Mandina the only blood-sucking fly seen was Tabanus taeniola. From Mandina to Quinella, the road lies through cultivated country with thin bush, but there are two swamps both surrounded with thick vegetation and high shady trees. Not far from Mandina, a single specimen of Chrysops longicornis, the only one seen during my tour, was obtained.

From Quinella $I$ went to Tendaba, a landing-stage on the river about three miles from Quinella, to await the Government steamer from Bathurst, as by this means it was possible for me to examine the Bintang Creek. At Tendaba I remained for two days and so had an opportunity of finding out more exactly the facts as to the occurrence and habits of blood-sucking flies at such landing-stages. There are no European factories here, but it is a recognized calling place for launches passing up and down the river. Considerable trade is, however, carried on by the natives, and a large quantity of ground nuts is shipped here on board schooners for Bathurst. The landing stage itself is at the end of a laterite escarpment, and consequently the bush in the immediate vicinity is very sparse, but the bank of the river, except for a clearing of less than 100 yards, is fringed with mangroves. The following blood-sucking flies were abundant:-Glossina palpalis, Stomoxys nigra, S. calcitrans, Lyperosia minuta, Tabanus taeniola and T. ditaeniatus. Glossina palpalis swarmed practically the whole day, but were not so numerous between 1 and 3 p.m. At no hour of the day from 7 a.m. to 6.30 p.m. was it possible to sit down without being persistently attacked by these insects, and when one did sit down it was necessary to have a boy with a "horse-tail" keeping a sharp look-out, especially round one's legs and ankles. Stomoxys and Lyperosia reserved their attentions for the horses, but were not very troublesome until after 3 or 4 p.m., when they were a source of great 
irritation ; all parts of the pony were attacked, but more especially the pasterns. This is due in great part to the fact that there are no muscles in this region capable of causing a twitching of the skin. The number of these insects may be gauged by the fact that, using a glass-bottomed box $1 \frac{1}{2}$ inches in diameter, I frequently caught four and sometimes five by simply placing the box over such a group. The great abundance of $G$.palpalis at such places being necessarily a source of danger, some considerable outlay for clearing measures is surely justified.

\section{(e.) Bintang Creek.}

This creek opens into the River Gambia, about 25 miles from Bathurst, and after a short but very tortuous course runs practically parallel with the river. Its length in British territory is, roughly, $50 \mathrm{miles,}$ and it is navigable all the year round for launches, drawing $6 \mathrm{ft}$. of water. At its mouth it is nearly a mile in width, but it gradually narrows until at Sandeng it is only about 50 yards wide. The tidal influence is marked throughout the whole course, and, as in the case of the main river where this occurs, the banks are clothed with a dense growth of mangroves trum end to end, except perhaps where villages are situated, and there sporadic trees of various kinds have sprung up. The country is very flat in this region, except at Bintang (fig. 10), where the town of that name is

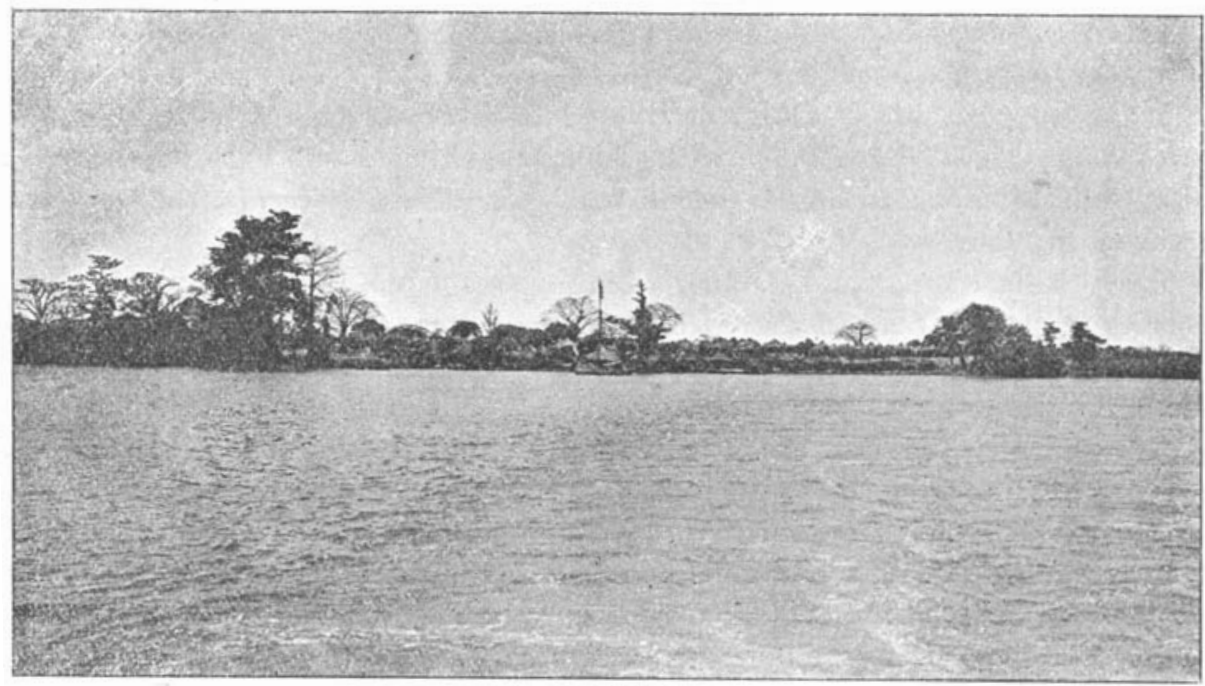

Fig. 10.-Town of Bintang, on the creek of the same name.

situated, and where there is a slight elevation of the bank. The only other town of any size is Kansala ; fig. 11 shows the wharf and landing stage of that town. This view is typical of all the landing stages on the creek; it shows how these are constructed and to what extent clearing has been done. Only sufficient mangroves have been cut down to clear a space on which to build the wharf and leave a small open part on each side for canoes. Apart from Glossina palpalis, the only blood-sucking fly seen was $\boldsymbol{T}$. socialis, and it is noteworthy that only in 
the Bintang Creek was this species caught during this tour. One specimen was obtained at Kansala and another at Sandeng. Glossina palpalis occurs, one may almost say with certainty, along the whole creek, but for the present, I have recorded on the map only actual localities where they were seen to fly on board, or where they were caught on shore. The mere fact of their being seen and caught at all times of the day and at all places on board the launch does not in itself justify the conclusion that they are as plentiful at one place as another, because, after flying on board, they may remain hidden for some time and re-appear near a place which might be free from them. Specimens were obtained on shore at Bintang, Kansala, Jarrol and Sandeng-the only four places where the launch remained long enough for one to go ashore to collect. A few other places I have indicated on the map, but there is little doubt that many more places might be with equal certainty included as haunts. It would be better,

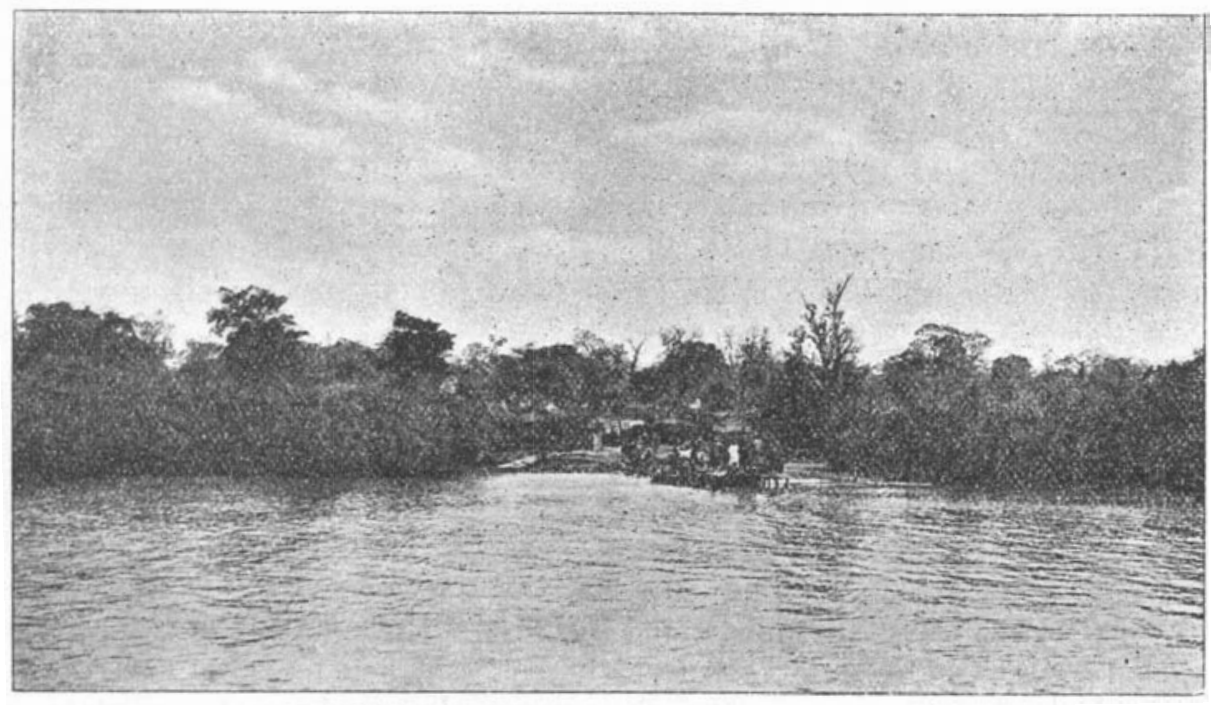

Fig. 11.-View of Kansala Wharf, to show the character and extent of clearing at the wharves in the Bintang Creek.

however, to have actual data before committing oneself to any sweeping assertion. The trip in the Bintang Creek served to bring out and emphasise several points at which I have hinted before, but which, up to now, did not present themselves in so concrete a form. His Excellency, the Governor, Sir George Denton and party, including the Gambia Company of the West African Frontier Force, were touring on the south bank of the river at this time and had occasion to cross the creek. For this purpose it was necessary for the Government steamer to go to Sandeng to transfer the party to Jarrol. At Sandeng there is a small jetty similar to that at Kansala (fig. 11), but at Jarrol the steamer is simply tied up alongside the bank. Now I have already stated that at all these places Glossince palpalis abounds and that the bush, in this case chiefly mangroves, is cleared only sufficiently to effect a landing. The risk, therefore, in transferring some 500 men under these conditions, is necessarily great, and at least 
to minimize this, some attempt should be made to clear an area so that embarkation might be made possible without, as at present, an accompanying swarm of tsetse.

The Government steamer, the "Mansahkillah," has two decks, the lower for native passengers and crew, and the upper for Europeans. With the exception of one cabin and saloon on the upper deck, all the sleeping accommodation is below. During this tour in the Bintang Creek, Glossina palpalis swarmed in all parts of the vessel, not being restricted to the lower deck to so great an extent as one sees on the stern-wheelers which ply on the Niger. Never before have I seen $G$. palpalis in euch numbers, and even on the upper deck saloon they were so troublesome that we had to have recourse to mosquito boots to protect our ankles. Though not to the same extent, this state of affairs obtains in many parts of the river, and the fact that a former master of this vessel died from sleeping-sickness, contracted on the Gambia, must not be overlooked. For this reason I should strongly recommend that erery cabin and saloon be made mosquito-proof with wire gauze. As a marked contrast, from this point of view, I add a photograph (p. 226) of another Government steam-launch, the "Rose," which was fitted up for surveying purposes by Lieut. Spicer Simson, R.N., and which has been made mosquito-proof in the after part-a most admirable arrangement.

A predatory spider, Plexippus paykulli, Aud., of the family ATtidae, inhabits the "Mansahkillah" in large numbers. These do not spin a web but conceal themselves in dark corners, cracks, or crevices of the vessel, and dart suddenly on their prey. Although Glossina palpalis was most abundant, still, there were other non-biting diptera present in the saloon, but it was observed that these spiders ignored the other forms and devoted their whole attention to $G$. palpalis, stalked them, and eventually captured not a few. The altack was usually made from the rear, but was occasionally frontal, the spider always attempting to pin down the wings. When this attempt failed, the tsetse, by a rapid movement of the wings, generally managed to escape, but when once the spider got a fair hold, it hung on tenaciously sometimes for over an hour, at the end of which time the tsetse, though not actually dead, was in a state of collapse, at least in the case of those under observation.

A very marked case of the effect of colour of clothing, in attracting or repelling Glossina, occurred during this trip. My companion, who in the earlier part of the day was wearing a white coat, and who was continually attacked by Glossina only in the legs and ankles, had occasion to change into a black coat. Soon after, he complained of being bitten on the back and arms, and at first thought that this was due to an increasing number of Glossina. After again changing his coat, he noticed that the bites on his back and arms decreased accordingly, and, to test the effect of this change of colour, he wore first one and then the other. In the same space of time, namely 10 minutes, I observed that whereas fifteen Glossina palpalis settled on the black coat, only two alighted on the white. The reason why one's legs and ankles are the chief points of attack is that the flies alight and settle unobserved for a time under the seat of the chair or under the table, and then dart quickly out to the nearest unprotected part. It is now known that Glossina can, and does, bite through moderately thick 
clothing, and very easily through woollen socks, so that in tsetse country the ankles should be well protected by some form of top-boot, e.g. mosquito-boots, or putties, but on no account should "shorts" be worn, as they render one very liable to bites behind the knees.

A third point in the habits of Glossina, as noticed on other occasions but emphasised during the Bintang tour, is the fact that movement has a decided attraction for tsetses. It is a matter of every day observation that, even in a place where tsetse are abundant, if everyone remains perfectly still few if any tsetse will leave their hiding places and come out to attack, but numbers will be lured from their retreats by any person walking slowly backwards and forwards. The same condition of affairs obtains in the case of cattle. What is more surprising is the fact that very few tsetse fly on board a launch when it is at anchor, even when it is moored alongside the bank at a tsetse-haunt. As soon, however, as it gets under weigh, they immediately swarm on board, flying even a distance of 100 yards in pursuit.

The essential points observed during my journey by launch to MacCarthy Island have already been referred to in connection with the vegetation on the river banks, so that it is necessary here to give only such records of blood-sucking flies as have not yet been noted.

South end of Elephant Island :-

Glossina palpalis.

Tabanus laverani.

Ballangar :--

Glossina palpalis.

Barijali :-

Glossina palpulis.

Tabanus taeniola.

Near Kai-ai :-

Glossina palpalis.

Tabanus taeniola.

Tabanus biguttatus var. croceus.

\section{(f.) Niumi Province.}

Sika (see Map) is a Mandingo town of moderate size and stands in a fairly extensive clearing ; it is situated some distance from the river and is surrounded by dense bush. According to the headman of the town, cattle live well here but horses die off soon after arrival. Glossina palpalis occurs even in the height of the dry season (1) in the camp, (2) in the bush separating the town from the river, and (3) in the mangrove swamp fringing the river bank. The people seemed well acquainted with sleeping-sickness, and strongly maintained that nearly every year one or more died from this disease. The first part of the road to Albreda is throngh thick dense bush, a veritable haunt of $G$. palpalis; further on, an extensive swamp consisting of numerous rice farms is crossed, and thick bush is again entered before reaching Albreda. This town was formerly a French possession but was ceded to the British in 1857 . Up till recently it was an important trading port, but now no Europeans are stationed there. The town 
itself is surrounded by bush, and the rest-camp, which is situated about 400 yards from the river, is separated from it by about 150 yards of clearing. In spite of this, however, numerous $G$. palpalis were seen in the camp, but these may have followed the native water-carriers from the village. Auchmeromyia luteola was also common in the camp. My pony had been waiting here for me for some days during the trip in the Bintang Creek, and on my return several Hyalomma acgyptium were found on it. The road from Albreda to Alijamadu runs parallel with the river bank the whole way, passing through Lamin, Tubab Kolon, and Sita Kunda. The nature of this part of the country may be described as open and park-like in character and there is extensive clearing and cultivation around all the towns and villages. Towards Alijamadu, there are large clusters of thick bush and Borassus palms similar to those described at Cape St. Mary. These may well be palpalis-haunts. The headman of this village, who is extremely intelligent, ventured the information that tsetse and large Tabanids may be seen here even in the dry season, but are much more abundant during the rains, as also are mosquitos. No horses are kept, and only a small herd of cattle, both, but especially the former, being subject to a form of disease the description of which was very suggestive of trypanosomiasis. I saw one tsetse in the camp, and although not certain, am strongly of opinion that it was Glossina morsitans. The dogs in this village seem to suffer badly from ticks, and the following species were obtained: Rhipicephalus sanguineus, Hyalomma aegyptium and Haemaphysalis leachi. Bed-bugs (Cimex rotundatus, Sign.) are also very common in the native houses; these the headman brought to me with great pride.

Shortly after leaving Alijamadu for Berrending, a belt of dense bush is encountered; this is immediately followed by an extensive swamp intersected by a creek, which is bridged. This creek is fringed by mangroves, which extend to the river, and is doubtless a palpalis-area. From this onwards to Bakkendik, the road passes through dense bush and seems a likely abode for tsetse. Round the town of Bakkendik itself, there is a considerable clearing and abundant cultivation. Quite a moderate herd of cattle was seen here, but the natives say that the rate of mortality is high. After leaving Bakkendik, the road passes through thin open bush and long grass, which is burnt in the dry season, but after about two-thirds of the way to Bintang has been passed, very thick bush with aerial creepers and a dense undergrowth of low palms, ferns, etc., is encountered. This is the top of another creek, and there are numerous pools of stagnant brackish water in the dry season. Glossina palpalis was caught here. The rest-camp lies about half way between Berrending and Buniadu. At Berrending, I saw a small girl with marked signs of advanced sleeping-sickness, and the chief, on being questioned, stated that the natives had some months previously assigned this case to "ceeno jankaro" ; they do not fear it and the girl lived as usual with her family. The road from Bakkendik to Berrending skirts the edge of a dense forest-the only one in the Colony-already described on page 190. The main route from Berrending to Duniajoe is viâ Essau, but there is a bush-path which runs throngh $M^{\prime} B o l l e t t$, and as this traverses the outskirts of the forest, I decided to go by it in the hope of seeing Glossina fusca, because, if this species does occur in the Colony, it must almost certainly be in this region. The path to 
M'Bollett is through a thin plantation of young trees with very little undergrowth; the village of M'Bollett, which is small, occupies a moderately large clearing in this thin forest growth. Shortly after leaving this village a belt of dense bush with an enormous amount of undergrowth, about 50 yards in width, is crossed, while onwards from this the vegetation consists of thick low scrub. The village of Jeni Kunda stands in the centre of a large clearing, while, beyond this, the thick low scrub continues to Duniajoe, with the exception of one part, which is intersected by a creek fringed with mangrove swamp where the water ebbs and flows with the tide. The forest behind Duniajoe teems with small game, as was shown by the number of skulls and horns lying about the various compounds. The natives say that it is almost impenetrable in most places, and that hunting is very difficult. From Duniajoe to Essau, the road traversed is for a certain distance, namely to Jeni Kunda, the same as that already described, while, shortly after leaving this town, the dense belt of bush mentioned before is again crossed in a different part. Just after emerging from this belt I saw $G$. morsitans alight on the pony's neck. After this, the bush is thin and open practically the whole way to Essau ; about half way, one Glossina morsitans was caught on the pony. Just before reaching Essau, a mangrove swamp is passed on the west, while the town itself is also surrounded by mangroves. It is worthy of note here that Todd and Wolbach found that 5.4 per cent. of the population were infected with Trypanosoma gambiense-the highest percentage found in any part of the Colony. They have recommended the removal of the town and this is certainly the best advice; if such a drastic step is found to be impracticable, at any rate extensive clearing ought to be done, as the place swarms with Glossina palpalis, and there is continual intercourse between this Province and Bathurst, through Essau.

I have discussed the various types of vegetation and the physical configuration of the whole Colony and Protectorate in a general way, but in the case of the part of the Niumi Province visited, considerable further detail has been added. This has been done advisedly because, from the point of view of Glossina and trypanosomiasis, this district presents an enormous field for enquiry. In most other parts of the country where Glossina palpalis and Glossina morsitans exist, there is a fairly definite distinction between the habitats of the two species. This does not obtain to the same extent in Niumi, as is evidenced by the notes and records already given. Here also is the only forest belt in the Colony and the only game reserve of any extent. It may be noted here that all officials of the Colony, who have travelled through this Province, are unanimous with regard to the improbability of taking a pony through it without its being infected with trypanosomes. The natives are all very emphatic that it is useless for them to procure ponies, as these almost invariably die within a year. This was the last district visited by me during my tour ; in fact, I left for England four days after finishing this trip, and it may be worthy of notice that, throughout my whole tour in the Colony, my own pony showed no signs of trypanosomiasis, although I did not dose him with mercury and arsenic, a precaution I always took in Northern Nigeria. Yet within a fortnight of my leaving the Colony or, in other words, within a month of the pony's first entering the Niumi Province, he showed 
distinct signs of infection and, when examined, was found to be suffering severely from trypanosomiasis, which was most probably contracted in this district. He was brought to England and is now, I understand, in the Velerinary Farm at Camden Town.

Almost the same state of affairs holds good with regard to cattle; a few may be seen in some of the villages, but in none are there large herds, such as may be seen in the other districts. This is due entirely to the fact that the rate of mortality is so high that the natives will not take the risk of importing them. Sleeping-sickness is also far from uncommon and, as already mentioned, the highest percentage for any village found by the Expedition of 1911 was at Essau, a village on the river bank in this Province. This area, therefore, being well circumscribed, is preeminently suitable for various lines of enquiry. It is practically certain that trypanosomiasis is responsible for the mortality amongst the horses and most probably also amongst the cattle. It is not at all certain, however, that the horses and cattle are infected with the same trypanosome, and further, the mortality amongst the latter might be due to a form of piroplasmosis. These points alone would justify the establishment of a temporary laboratory, but in addition to this, the question of reservoirs is an all-important one, and, in this region, ample scope could be found for such work, in fact it is not too much to say that practically every species of animal found in the Gambia, could be obtained here.

We are entirely ignorant of the breeding places of Glossina in the Gambia, and no area could be more suitable for such an investigation than the Niumi Province. Consequently, to the Veterinary Surgeon who wishes to study the origin, cause, or treatment of protozoual disease in horses and cattle; to the Protozoologist who wishes to study the origin and transmission of trypanosomiasis in man ; to the Medical Officer who wishes to follow the course and curative treatment of sleeping-sickness ; or to the Entomologist who is desirous of investigating the habitats, life-history, and bionomics of blood-sucking insects and other arthropods, Niumi Province, so easy of access from Bathurst, opens up unlimited opportunities for research.

\section{Records of Blood-Sucking Arthropods from the Gambia.}

The following list of blood-sucking arthropods has been drawn up to include, as far as possible, all previous records, and so render this report complete in this respect up to the date of publication. It will also serve to show how meagre our information on this subject is, in spite of the large number of species which occur in the Colony and their wide distribution, and may help to stimulate others to fill in the numerous blanks which at present exist. The records of Glossina made by the author are not included here, as they have already been detailed and may be seen at a glance on the appended map. The other records here given have also been included on the map, when the localities assigned to them have been definite enough to admit of identification. Apart from Glossina, however, all the other species collected by the author are included. The generic names here given for the mosquitos are not those assigned to the various species 
in the original report on the collection made by the late Dr. Dutton, but are in accordance with the classification adopted at present by Mr. F. W. Edwards, of the British Museum. It is rather remarkable that no Hippoboscidas have been recorded from the Gambia, nor did I see a single specimen during my tour.

\section{Family TABANID As.}

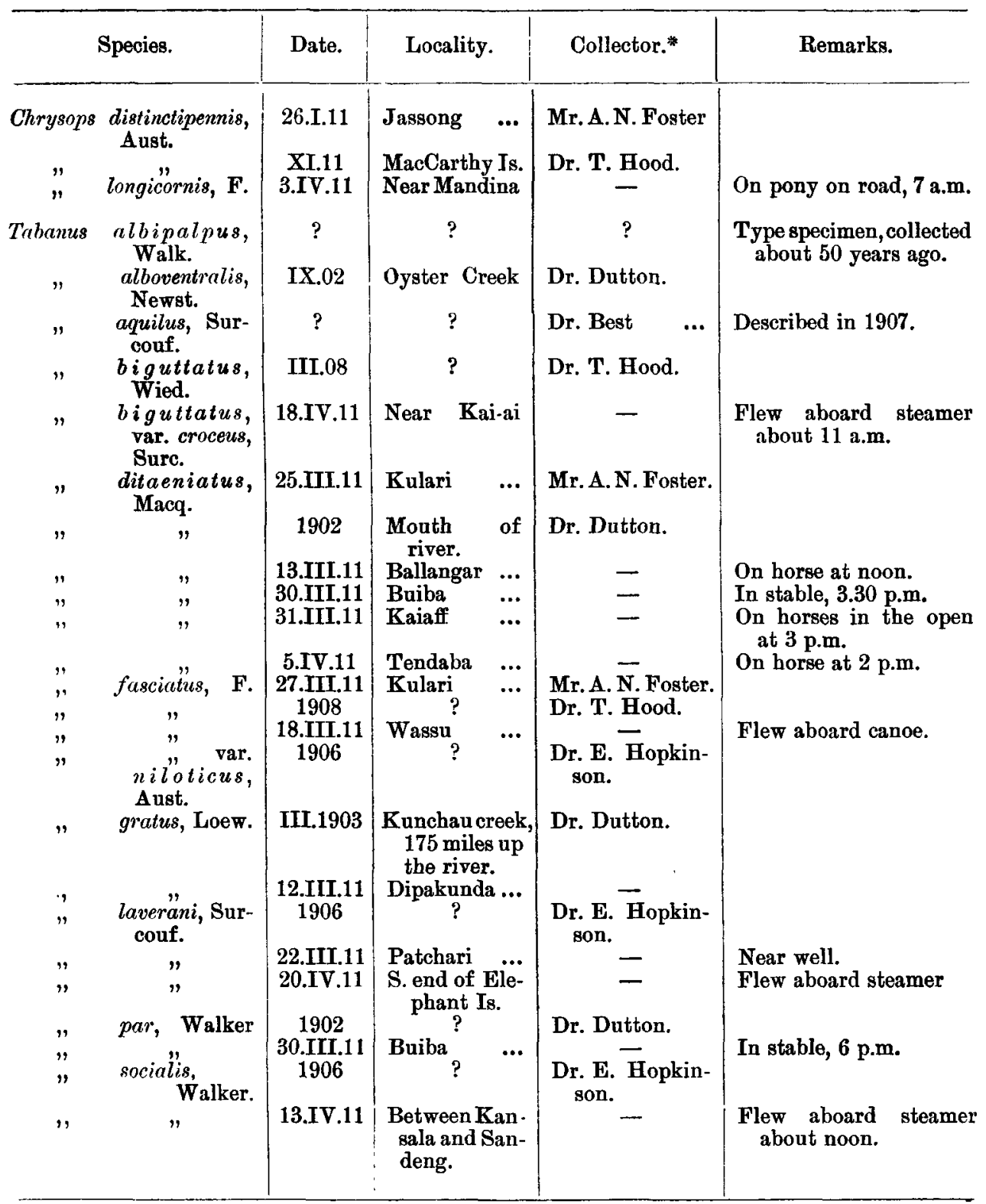

* Where no name is given the species was collected by the author. 
Family TABANIDAE-continued.

\begin{tabular}{|c|c|c|c|c|c|}
\hline \multicolumn{2}{|c|}{ Species. } & Date. & Locality. & Collector.* & Remarks. \\
\hline $\begin{array}{c}\text { Tabanus } \\
",\end{array}$ & $\begin{array}{l}\text { sufis, Jaen.... } \\
\text { taeniola, } \quad \mathbf{P} \text {. }\end{array}$ & $\underset{?}{19.1 X} 02$ & Oyster Creek & $\begin{array}{l}\text { Dr. Dutton. } \\
\text { Dr. T. Hood. }\end{array}$ & \\
\hline$-\mapsto$ & $n$ & $?$ & $?$ & $\begin{array}{l}\text { Dr. E. Hopkin- } \\
\text { son. }\end{array}$ & \\
\hline$"$ & $"$ & $\stackrel{?}{?}$ & $?$ & Dr. Dutton. & \\
\hline$"$ & $"$ & $\begin{array}{l}\text { 25.III.11 } \\
12 . \mathrm{III.11}\end{array}$ & $\begin{array}{ll}\text { Kulari } & \ldots \\
\text { Sokoto } & \ldots\end{array}$ & Mr. A. N. Foster. & \\
\hline$"$ & $"$ & 15.III.11 & N'Jau $\quad \ldots$ & - & On horse at 4.30 p.m. \\
\hline$"$ & $"$ & 16.III.11 & Amodi & - & \\
\hline$"$ & ," & 16.III.11 & Tento $\quad \ldots$ & - & In stable at 10.30 a.m. \\
\hline$"$ & $"$ & 17.III.11 & Jalokunda ... & $\overline{-}$ & In stable at 4 p.m. \\
\hline$"$ & $\ddot{"}$ & $\begin{array}{l}\text { 18.III.11 } \\
\text { 21.III.11 }\end{array}$ & $\begin{array}{l}\text { Wassu ... } \\
\text { Boraba cross- } \\
\text { ing to Mac- } \\
\text { Carthy Is. }\end{array}$ & - & On river in native canoe. \\
\hline$"$ & $"$ & 22.III.11 & & 一 & Near well. \\
\hline$"$ & $"$ & $\begin{array}{l}\text { 24.111.11 } \\
\text { 27.III.11 }\end{array}$ & $\begin{array}{l}\text { Tenentara } \\
\text { Sukuta }\end{array}$ & - & In stable, 5.30 p.m. \\
\hline$"$ & $"$ & 30.III.11 & Buiba $\quad \ldots$ & - & In stable, 10.30 a.m. \\
\hline$"$ & $"$ & 31.III.11 & Kaiaff & - & On horse in open, 4 p.m. \\
\hline " & " & 2.IV.11 & Mandina $\quad .$. & - & On horse, 8.15 a.m. \\
\hline$"$ & $"$ & 5.IV.11 & Tendaba $\ldots$ & - & On horse, 9.30 a.m. \\
\hline$"$ & $"$ & 18.IV.11 & $\begin{array}{l}\text { Between Bal- } \\
\text { langar and } \\
\text { MacCarthy } \\
\text { Is. }\end{array}$ & - & $\begin{array}{l}\text { Flew aboard the steamer } \\
\text { in numbers the whole } \\
\text { way. }\end{array}$ \\
\hline$"$ & $"$ & 19.IV.11 & Near Barijali & $\bar{N} \bar{T}+$ & Flew aboard the steamer. \\
\hline ., & $\begin{array}{l}\text { var. } \\
\text { variatus, } \\
\text { Walk. }\end{array}$ & 25.III.11 & Kulari $\quad \cdots$ & Mr. A.N. Foster. & \\
\hline$"$ & ? n. sp. $\quad \ldots$ & 22.III.11 & Patchari & - & Near village well. \\
\hline$"$ & $" \quad \ldots$ & 23.III.11 & Brikama & - & Near village well. \\
\hline $\begin{array}{l}\text { Haematop } \\
\text { Walk. }\end{array}$ & ta $"$ dernia, & $\begin{array}{c}\text { 26.III.11 } \\
\text { 2.III.11 }\end{array}$ & $\begin{array}{l}\text { Jarreng } \\
\text { Bakau }\end{array}$ & $\overline{-}$ & On horse. \\
\hline
\end{tabular}

Family MUSCIDA.

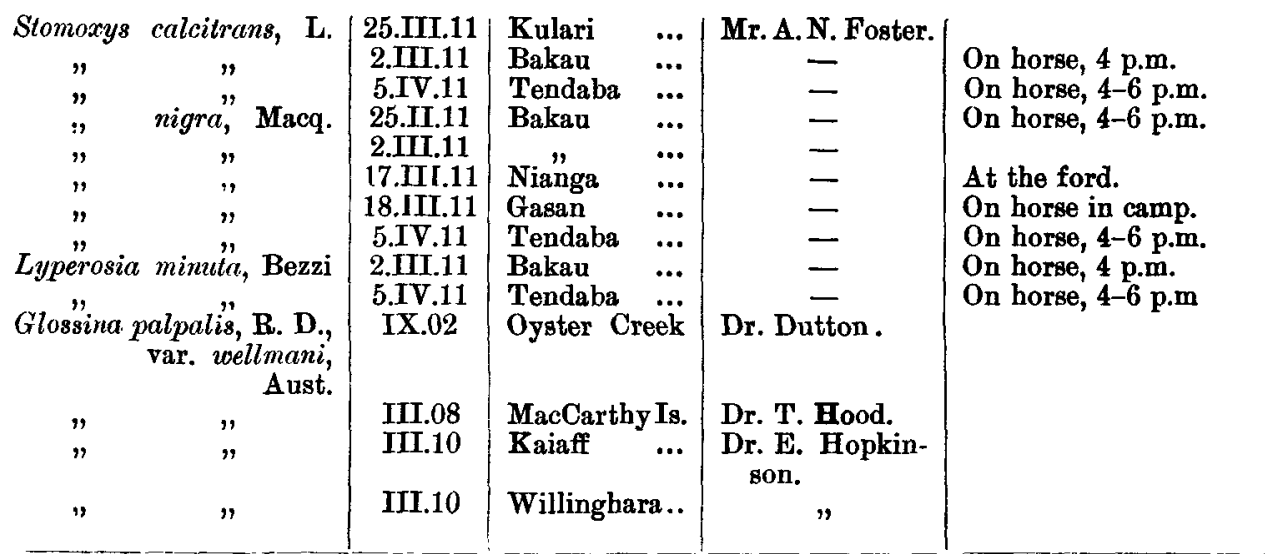

* Where no name is given the species was collected by the author. 
Family MUSCID $A$ s-continued.

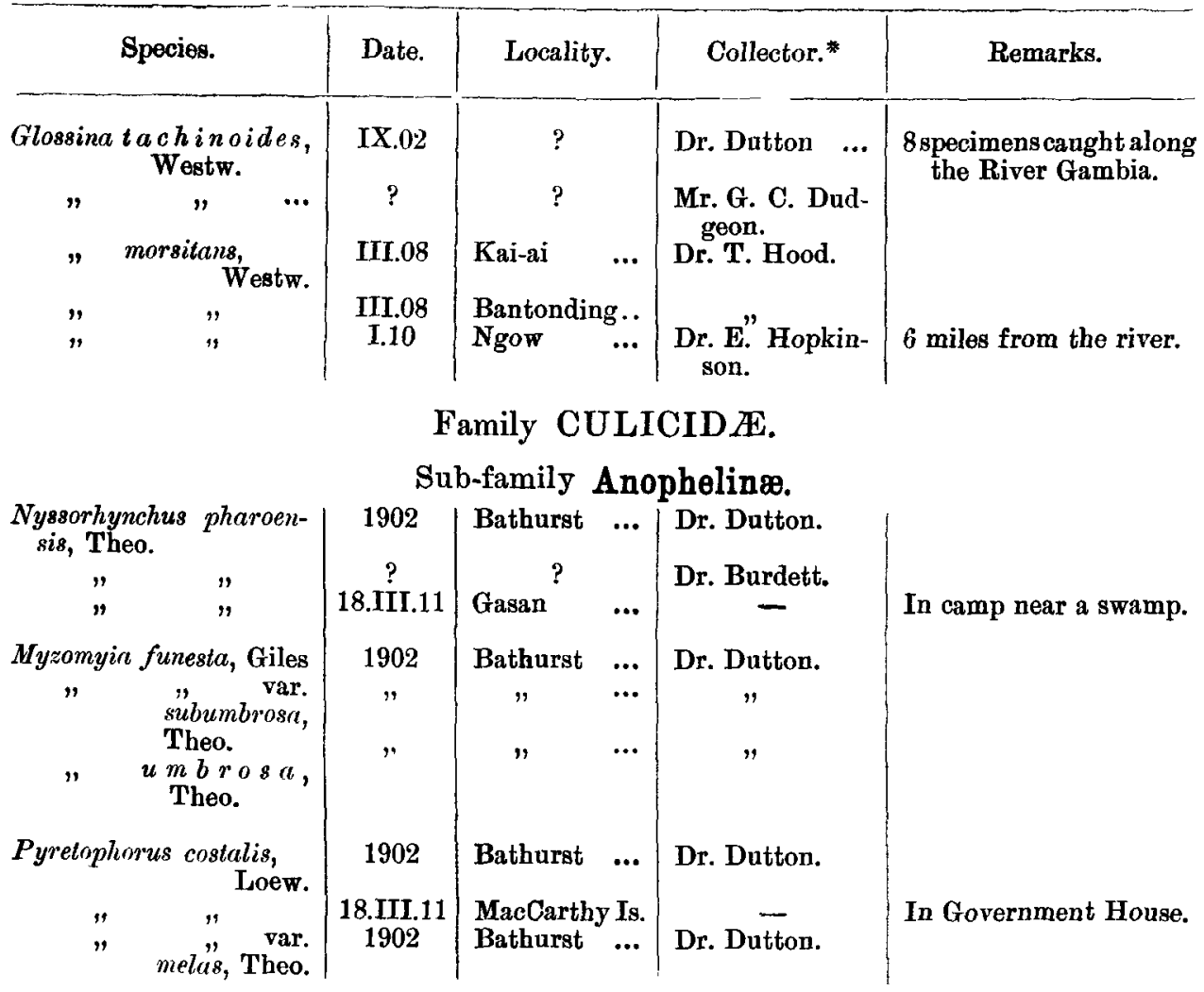

\section{Sub-family Culicinæ.}

\begin{tabular}{|c|c|c|c|c|c|}
\hline & & & & & \\
\hline $\begin{array}{c}\text { Culex annulioris, Theo., } \\
\text { var. gambiensis, } \\
\text { Theo. } \\
\text { duttoni. Theo. }\end{array}$ & 1902 & Bathurst & $\cdots$ & Dr. Dutton. & \\
\hline$" \#$ & 2.IV.11 & $"$ & $\cdots$ & Dr. Franklin ... & (See Culex tigripes.) \\
\hline $\begin{array}{l}\text { invidiosus, Theo. } \\
\text { fatigans, Wied. ... }\end{array}$ & 1902 & $"$ & $\cdots$ & Dr. Dution. & \\
\hline$" \quad "$ & 2.IV̈.11 & $"$ & $\cdots$ & Dr. Franklin '... & $\begin{array}{l}\text { Bred from larvæ taken } \\
\text { from casks containing } \\
\text { rotting Baobab fibre. }\end{array}$ \\
\hline $\begin{array}{l}\text { decens, Theo. ... } \\
\text { " quasigelidus, } \\
\text { Theo. }\end{array}$ & $\underset{1902}{23.111 .11}$ & $\begin{array}{l}\text { Brikama } \\
\text { Bathurst }\end{array}$ & $\ldots$ & Dr. Dutton. & Abundant in rest-house. \\
\hline $\begin{array}{l}\text { Mansoninides uniformis, } \\
\text { Theo. }\end{array}$ & 1902 & Bathurst & $\cdots$ & Dr. Dutton. & \\
\hline$"$ & 27.III.11 & Kulari & $\cdots$ & Mr. A. N. Foster. & \\
\hline Scutomyia sugens, Wied. & 1902 & Bathurst & ... & Dr. Dutton. & \\
\hline Stegomyia fasciata, Fabr. & 1902 & Bathurst & ... & Dr. Dutton. & \\
\hline$"$ & IV.11 & $"$ & $\cdots$ & & In military barracks. \\
\hline
\end{tabular}

* Where no name is given the species was collected by the author. 
Sub-family Uranotaeniinæ.

\begin{tabular}{l|c|c|c|c}
\hline Species. & Date. & Locality. & Collector.* & Remarks. \\
\hline $\begin{array}{l}\text { Uranotaenia albocephala, } \\
\text { Theo. }\end{array}$ & 1902 & Bathurst $\ldots$ & Dr. Dutton.
\end{tabular}

Sub-Family Corethrinæ.

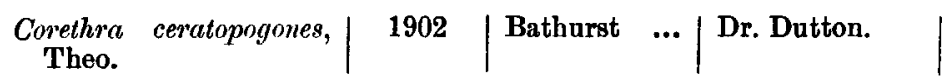

Family CHIRONOMID无.

\begin{tabular}{lll|l|l|l|} 
Culicoides sp. & $\cdots$ & $\cdots$ & 23.III.11 & Brikama & $\cdots$
\end{tabular} \mid

Family PSYCHODID $Æ$.

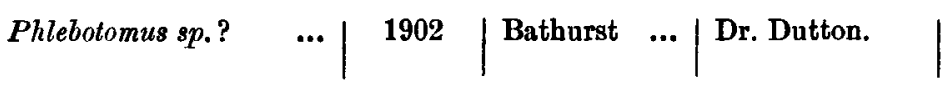

Family PULICID F.

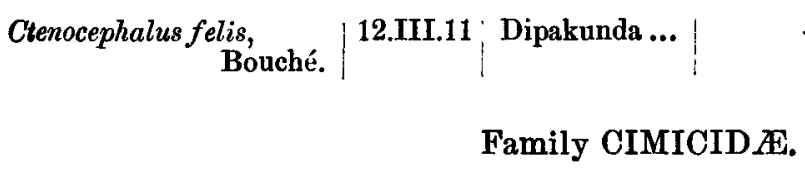

Cimex rotundatus, Sign. $\mid$ 22.IV.11 $\mid$ Alijamadu ... $\quad-\quad$ In native hut.

\section{IXODOIDEA.}

Ticks are far from abundant towards the end of the dry season, but are said to be very troublesome at the beginning of the rains. The following were obtained by the author in March and April, 1911.

\begin{tabular}{|c|c|c|c|c|}
\hline Hyalomma aegyptium, $\mathbf{L}$. & 2.III.11 & Bakau $\quad$... & - & On horse. \\
\hline$"$ & 21.IV.11 & Albreda & - & On horse. \\
\hline$"$ & 22.IV.11 & Alijamadu ... & - & On dog. \\
\hline $\begin{array}{l}\text { Amblyomma variegatum, } \\
\text { F. }\end{array}$ & 2.III.11 & Bakau $\quad$... & $\cdots$ & On horse. \\
\hline $\begin{array}{l}\text { Rhipicephalus sanguineus, } \\
\text { Latr. }\end{array}$ & $22.1 V .11$ & Alijamadu ... & - & \\
\hline $\begin{array}{l}\text { Haemaphysalis leachi, } \\
\text { Aud. }\end{array}$ & 22.IV.11 & Alijamadu ... & - & On dog. \\
\hline
\end{tabular}

- Where no name is given the species was callected by the author. 


\section{NATIVE NAMes OF BLOOD-SUCKING lNSECTS AND OTHER Arthropods.}

$\Lambda$ knowledge of the native names of blood-sucking insects is necessary to anyone who may try to obtain any information with regard to their occurrence, habits, etc., from the natives themselves. It is also essential if any attempt is to be made to instruct the natives in the rôle played by these in the dissemination of disease, a course which I strongly advocate. Finally, a study of such names, which often describe some habit or peculiarity of the insect as observed by them, is often instructive. For these reasons $I$ have tried to collect the various names used by the different tribes which inhabit the Grambia, but of course this list must necessarily be incomplete. I have, however, included it in this report in the hope that anyone who may notice any fault or omission will kindly point such out so that it may be rectified.

\begin{tabular}{|c|c|c|c|c|c|c|c|c|}
\hline - & Mandingo. & & Jolloff. & & Foulah. & Teucolo & & Jolah. (8) \\
\hline Sandfly $\ldots . \quad \ldots$ & Bokaro & $\ldots$ & Mutumut & & & Bokari & ... & \\
\hline Mosquito & Susula... & ... & Yoi & $\ldots$ & Bodi & Bodi & ... & \\
\hline Flea & Jattocolo & $\cdots$ & Fel & $\cdots$ & & $\mathrm{Fel}$ & $\ldots$ & \\
\hline $\begin{array}{lll}\text { Jigger } & \ldots & \ldots\end{array}$ & Jigger ... & $\ldots$ & Jigger (6) & & & Jigger & $\ldots$ & \\
\hline Tick $\quad \ldots$ & Meto ... & ... & Wetein & $\cdots$ & & Kotu & $\ldots$ & \\
\hline Bed Bug & $\begin{array}{l}\text { Dabo ... } \\
\text { Babar ... }\end{array}$ & $\ldots$ & Mata & $\cdots$ & & Nyaki & $\ldots$ & \\
\hline Lice $\quad \ldots \quad \ldots$ & Karanko & $\cdots$ & Tein & ... & & Bamdi & ... & \\
\hline Large Tubanid & $\begin{array}{l}\text { Sujolo (1) } \\
\text { Siti jolo (2) }\end{array}$ & $\begin{array}{l}\cdots \\
\cdots\end{array}$ & \} Koss & $\ldots$ & Kaifal & Pechu & $\ldots$ & \\
\hline Small Tabanid ... & Jolo $\quad \ldots$ & $\ldots$ & Koss & $\cdots$ & & Pechu & $\ldots$ & \\
\hline $\begin{array}{lll}\text { Tsetse } \quad \ldots & \{\end{array}$ & $\begin{array}{l}\text { Jolo } \ldots \\
\text { Congo fin jolo } \\
\text { Jolo messem }\end{array}$ & (3) & $\left\{\begin{array}{l}\text { Koss } \\
\text { Jolo }\end{array}\right.$ & $\cdots$ & Y Lulu & Njol & ... & \\
\hline Sleeping Sickness & $\begin{array}{l}\text { Ceeno jankaro } \\
\text { Kanta bero }\end{array}$ & $\begin{array}{l}(5) \\
\cdots\end{array}$ & $\begin{array}{l}\text { Heribat ( } 7 \\
\text { Neluan }\end{array}$ & & \} Doingul... & $\mathrm{Kaji}$ & ... & \\
\hline
\end{tabular}

1. The jolo of the horse (suo).

2. The jolo of the "siti "-described to me as a "large bush animal."

3. The jolo of the monkey (congo).

4. The small jolo.

5. Both these terms are used by the Mandingoes. "Kanta bero" means " neck stontes," i.e., enlarged glands, while "ceeno jankaro" is literally "sleep sickness." It is averred by those who have studied the language that this latter term was not introduced to translate the English phrase, but was used by the natives prior to our introduction of the term.

6. The word "jigger" seems to be universal.

7. These two terms are used by the Joloffs to denote the two stages. "Heribat" is always translated by " the presence of bumps," i.e., enlarged glands, whereas " neluan " denotes the actual lethargic stage.

8. Unfortunately I did not get the Jolah equivalents, but $I$ have included this column so that they may be afterwards added to complete the vocabulary. 


\section{ViII. Bionomics of Glossina.}

In the Colony of the Gambia, only two species of Glossinu, namely, palpalis and morsitans were observed by the author, and the chicf points of bionomic importance have been given in more or less detail in the general narrative. It may be well, however, to recapitulate these.

\section{(a.) Glossina palpalis.}

Haunts.-Wherever mangroves exist one is almost certain to find palpalis, but careful search failed to reveal either pupae or empty pupal cases. This is not surprising, as mud is the chief constituent in a mangrove swamp. At the time of my visit to the Colony, the river level was practically at its minimum, and consequently many small creeks were dried up, and areas which would be swamps during the dry season, were baked hard by the sun and much cracked. If, however, as is probable, the chief breeding period is during the rains, the breeding grounds must be removed some distance from the actual river basin, and the tsetse must follow the receding water, as they are seldom found in the regions which would correspond to the water-level during the rains. In addition to the mangrove area, however, there are scattered over the Colony numerous clusters of dense bush with abundant low undergrowth. The soil in these places consists of decaying humus, and is moist throughout the whole year, even in some places retaining a small amount of surface water. These places are always tsetse-haunts, and as there can be little doubt that they form centres for the dispersal of tsetses, it is to these that attention should first be directed when any clearing is contemplated. A good example of this is to be seen at Bakau and elsewhere at Cape St. Mary, a description of which has been given above.

Abundance.-In most places they attack singly, or at any rate, in very small numbers, but occasionally, in certain places, they literally swarm around, and it is with the greatest difficulty that one can avoid being bitten. Cases of this description were noted on the launch in the Bintang Creek, at Wassu and Tendaba; but this is not always an infallible sign of actual numerical excess over other places, being often due to other factors, e.g., movement.

Movement.--It is a matter of almost commonplace observation that tsetse are much more active and pertinaceous in their attacks on moving than on stationary objects, and for this reason, it seems fair to conclude that they rely more on their sense of sight, than on any other, in selecting their unwilling host. In a tsetse-haunt, if one remains absolutely motionless, in the majority of cases, not a single insect will be seen, but as soon as one begins to walk backwards and forwards, they at once dart out to attack. The same is to be observed in the case of horses and cattle. A similar condition of affairs holds good with regard to canoes; if these be anchored or tied up, one is comparatively immune from attack, but as soon as paddling is commenced, hordes of tsetse swarm around; a good example of this was observed at Wassu (p. 202). Even more noteworthy 
is the fact that this holds true for large launches and steamers; this was very marked in the Bintang Creek. When the ship was approaching the river bank, swarms of tsetse flew on board, but if the vessel were actually tied up, few if any were seen, whereas as soon as the steamer cast off, tsetse at once renewed their attacks. This must be borne in mind in the selection and clearing of any parts in a tsetse area, such as wharves, ferries, etc., where there necessarily is considerable movement. In the Gambia, for instance, at the wharves which are used for loading ground nuts, there is a continual stream of natives passing to and from the schooners or steamers. This state of affairs furnishes ideal conditions for attack by tsetse.

Range of Flight.-As is well known, $G$. palpalis prefers to remain in the shade and near the ground, preferably in low scrub, and darts out into the open in the full sunlight only when in search of a meal. The maximum distance to which a tsetse will venture into an area with no shade is of great importance in delimiting clearings. Various estimates have been given, but although one has seen tsetse in camps separated from the bush by over 200 yards of clearing, it is not fair to assume that this distance was actually and deliberately traversed in one flight. It is quite possible that these isolated examples followed the natives or horses, a mode of procedure which they often adopt. On one occasion, however, when on board a launch more than 100 yards from the beach, I saw a $G$. palpalis fly on board in the cool of the afternoon, and in view of this and similar observations, 150 yards may be put down as the lowest estimate for clearing, though 200 yards, if possible, should be aimed at.

Effect of Sun.-G. palpalis, more than most other insects, is easily killed by heat, and cannot stand much exposure to the direct rays of the sun. When a number of insects of various kinds are transferred from a net into glass-bottomed boxes, prior to going to camp, it is almost invariably found that the tsetse are the first to succumb to the heat; in fact, if one is out for any considerable length of time, it is difficult to keep these flies alive without making a few air holes in the lid of the box and keeping it in a cool place.

Clothing.- There is now no question but that tsetse can, and do, bite through cotton and woollen clothing, and those even if of a thick texture, e.g., heavy tweed trousers. In many cases one has noticed that these insects have a predilection for certain colours, especially black, and a good illustration of this has been cited on page 210. In tsetse-infested areas, the ankles should be specially protected. Putties or leggings worn with riding breeches are ideal, but, as was mentioned before, "shorts" should not in any circumstances be worn. Khaki has many advantages, and of dark colours, is probably one of the least attractive to this species.

Enemies.-The question of the natural enemies of the tsetse is an all-important one, but it is vers difficult to get reliable information on the subject. During my tour in the Gambia, I examined the stomach-contents of a large number of birds 
whose food consisted of insects, but in no case could I with certainty identify any remains of Glossina. As already noted, however, 1 observed in the Government steamer an Attid spider attack and kill numerous tsetse, and this species of spider seemed to show a distinct predilection for $G$. palpalis, although several other species of Diptera were almost equally abundant. It is very doubtful if this is of actual importance, but, as a fact in the bionomics of tsetse, may be recorded here.

Daily Prevalence.-This species was caught at all hours of the day, but is most persistent and vigorous in the forenoon. From 5.30 to 9 in the morning they are not very troublesome; from 9 a.m. to about 1 p.m. they attain their maximum of activity, while from this time onwards to about 4 p.m. they are much more lethargic. After this period they again renew their activities until dusk.

Reproduction.-As having a bearing on the season of reproduction, it may be noted that two G. palpalis were caught in coitu on March 18th at 3.30 p.m.

\section{(b.) Glossina morsitans.}

Most of the facts given for $G$. palpalis hold good for G. morsitans, but the following notes will illustrate where these differ.

Haunts.-This species is seldom or ever found in the same regions as $G$. palpalis, but in the Niumi Province, where there is no line of demarcation between the types of habitat, and where they even intermingle, both species are equally abundant, and the actual nature of the bush gives little or no clue as to which may be expected. Apart from this area, as soon as one leaves the river bank, with its mangrove fringe and its accompanying belt of thick bush, and enters the region of thin bush with little or no undergrowth, one may expect to find G. morsitans. Wherever, also, there is a laterite outcrop, with consequently little or no surface moisture and very stunted vegetation, one may safely conclude that G. morsitans will be found; but if the outcrop is very rocky and bears only thin bamboos, neither species is to be seen. Typical habitats have already been described in this Report, while fig. 7 gives a good idea of an actual locality. The distance which this species will exist away from water has often been commented upon, and in the Gambia, I have captured specimens fully two miles from the nearest pool of water and as far distant from the nearest village well.

Abundance.-This species is seldom found in great numbers, but on two occasions, cited on pages 201 and 207 , they occurred literally in swarms and seemed to emit a much more pronounced buzzing sound than similar hordes of G. palpalis ; in fact, on one occasion, in moonlight, their approach was distinctly suggestive of a small swarm of bees, the pony becoming restive even before they actually alighted on him. 
Movement.-The notes given with regard to $G$. palpalis apply equally well to this species, as also do those on range of flight and on clothing.

Effect of Sun.-This species is not so susceptible to the sun's rays as is G. palpalis.

Daily Prevalence.-I had not the same opportunity of studying this point in the Gambia, never having remained very long in a morsitans-area, but from observations elsewhere and scattered records in the Gambia, I am of opinion that the lethargic afternoon period does not obtain so markedly as in G.palpalis. Noteworthy in this connection is the case cited on page 201, when, on a moonlight night, while crossing a dried up swamp about 10 p.m., we were literally attacked by a swarm of quite 100 to 150 , whereas, when we were crossing the same place in the afternoon at 5.30 , not a single specimen was seen.

Prey.-There can be little doubt that G. morsitans attacks man and animals with equal avidity, but the case mentioned on page 207 is worthy of consideration. On this occasion when riding round a sharp bend in the road I came suddenly upon a large troop of dog-faced baboons in an open clearing of considerable size ; these slowly scampered away, but left in their train an enormous number of $G$. morsitans, which had evidently followed them from the surrounding bush. They were, in some cases, over 400 yards from shade, and that at practically the hottest part of the day. Never have I seen as many G. palpalis so far away from shade at a similar hour. The predilection, if such it may be, of tsetse for monkeys has been noted by the Mandingoes, for they have named these insects "congo fin jolo" or "the biting fly of the monkey." An examination of the blood of these baboons as a potential reservoir of trypanosomes might well repay the trouble. It is not at all evident why the rate of mortality amongst cattle is so high and still higher amongst horses in the Niumi Province. It is certainly not due to an overwhelming excess in the number of $G$. morsitans, but may in part be due to the fact that there is no region beyond the river area to which cattle can be withdrawn in the rainy season, and consequently they have to stand or fall under the full tsetse scourge during this period. The large amount of game confined in this small area may, however, act as a reservoir, and as these form the food supply of the tsetse, the percentage of infective morsitans would be relatively high, which might account for the enormous mortality. The same may apply to $G$. palpalis and the large percentage of human trypanosomiasis infections in Essau, for example. At any rate an examination of the blood of such game might well reward the investigator. Another fruitful line of research may-be indicated here, namely the part played by Stomoxys as a protozooal carrier.

\section{Remedial Measures and Recommendations.}

Beyond pointing out that this town is by no means free from mosquitos, it is not my intention to suggest anything with regard to Bathurst, as this is the province of the Senior Sanitary Officer, and as remedial measures are being very 
efficiently carried on by the Senior Medical Officer. In view of the recent epidemics of yellow fever, both in Bathurst itself and in other towns on the coast, some drastic measures should be put into effect. The modus operandi of such work has been published often enough and is being adopted on a small scale in Bathurst, but the time has now come when further legislation is necessary and also a much larger sanitary staff to cope with these operations.

Sleeping-Sichness Camps.-I do not propose dealing at any length with this subject, but in view of Dr. Hood's minute forwarded to me by the Acting Governor, I feel it incumbent on me to add the following notes. There is considerable diversity of opinion as to the necessity for these camps, but this point will soon be settled by the Senior Medical Officer. If such are to be established, the first consideration is a suitable site. Several factors must be taken into account in this connection, but the predominant one is that of medical supervision. As pointed out to me by Dr. Hood in conversation, the only Medical Officer available for such work was stationed at Bathurst, but since that time another has been posted at the new hospital at MacCarthy Island ; consequently, if no special staff be appointed for this work, camps are possible only in the vicinity of these two places. This restriction does not, however, invalidate the main issue, as, apart from it, the two most suitable situations are those just mentioned. I examined the whole area known as the "Cape" and have already given a general idea of its vegetation and insect fauna. I have also stated that there is no reason why a sleeping-sickness camp should not be established here, even if the European residential headquarters be transferred from Bathurst. There is an extensive area available, but as this is of purely local interest and I have already expressed an opinion as to the most favourable site in my report to Dr. Hood, there is no necessity for me again to enter into details. Apart from the question of accessibility to Bathurst and of its being a suitable locality for segregation, it is an ideal place for a laboratory, and work could be carried on there under the most favourable climatic conditions in the whole Colony. As to a second camp in the MacCarthy Island district, I do not think that the island itself is in any way suited for this purpose. As already stated in dealing with this island, there is an enormous amount of bush and a large area is under water during the wet season. Glossina palpalis is abundant practically all over the island, and as there is continual intercourse between both sides of the river and the island itself, a camp in this situation would be a source of great danger. For these reasons, any proposal to establish a sleeping-sickness camp on MacCarthy Island should be at once negatived. On the north bank, however, in the vicinity of the town of Manna, there is an ideal area for such a camp, inasmuch as this is removed from the river, and a site could be selected which would not in the least interfere with the main trade routes. Such a camp would be within easy reach of the MacCarthy Hospital where laboratory work could be effected.

Removals. - Dr. Todd has forestalled me in suggesting that the town of Essan should be removed; its present situation is surrounded by mangrove swamp swarming with tsetse at all seasons. A site could easily be selected in the 
vicinity, and a clearing made of all bush over an area of 200 yards outside the limits of the town; further, I would suggest that the same should be done with the village of Waslunga at Cape St. Mary.

Clearing.-Much could be done at very little expense to minimise the risk of the spread of sleeping-sickness by some judicious clearing at wharves, ferries, \&c. Details of various places have already been given, but the following wharves are of special importance :-Kerewan, Ballangar, Kauur, Kai-ai, Wassu and Tendaba. The following ferries should also be cleared of bush :-Lamin Koto, Boraba, Faraba and Essau. In all these places, the bush or mangroves, as the case may be, should be cut down on all sides for a distance of at least 150 yards from the outermost house or store, or in the case of ferries, from the landing-stage. Of a more general nature, but even more important, are Bakan and MacCarthy Island. The nature of the vegetation around Bakau has already been referred to, but I might point out that it is not at all necessary to cut down the large trees but only the undergrowth and branches to a height of 10 or perhaps 15 feet, so that the sun's rays may have access to the soil. This work could be commenced early in the dry season, and the brushwood burnt on the ground cleared, so as to destroy any pupae which might be lurking there. The same applies to MacCarthy Island, but I would suggest that the nearest cluster of bush should not be closer to the new hospital at one end, or to the trading station at the other, than 400 to 500 yards.

Rest-Houses.-The rest-camps (fig. 12) in the Gambia are certainly better than

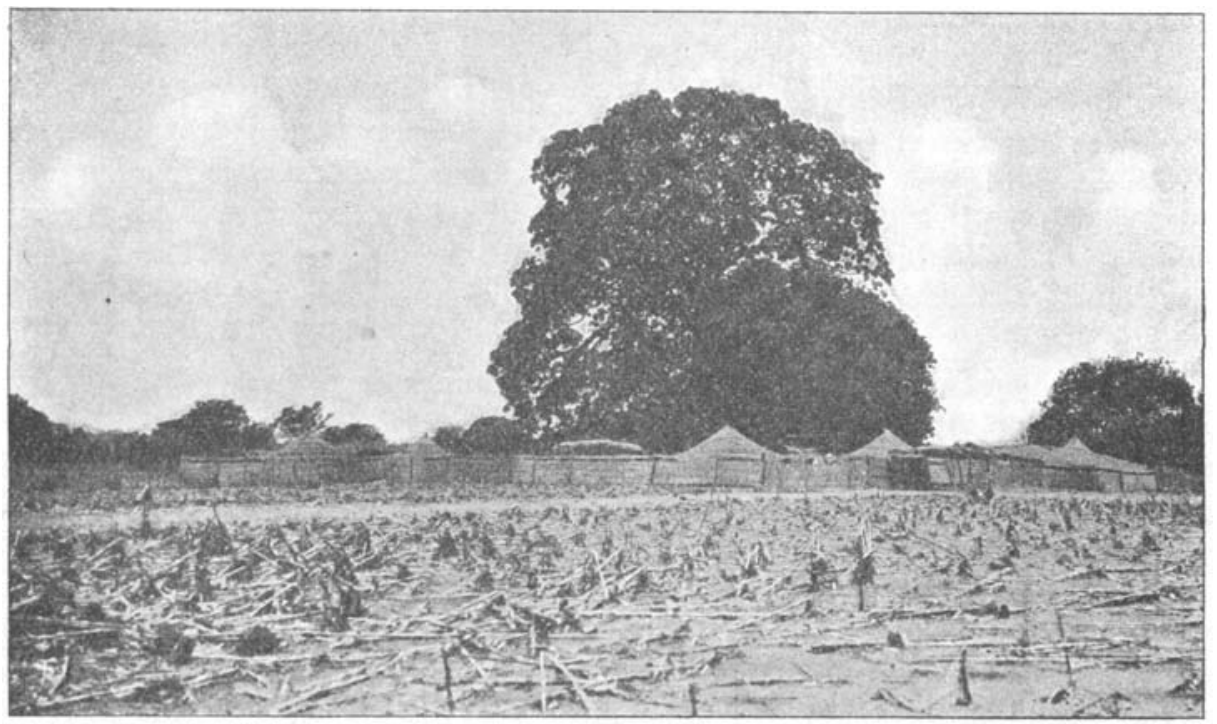

Fig. 12,-Typical rest-camp in the Gambia.

any others $I$ have seen in West Africa, but unfortunately a few have mud walls. This fact has been remarked elsewhere, and as these camps are not used in the wet scason, mud should certainly be avoided in their construction if possible. 
Launches and Steamers.-The mosquito-proofing by wire gauze of all saloons and cabins in vessels plying on the river is strongly to be recommended. A very good example of what can be done in this respect at very little expense and without in any way interfering with the utility of the vessel, is seen in the surveyinglaunch "Rose" (fig. 13).

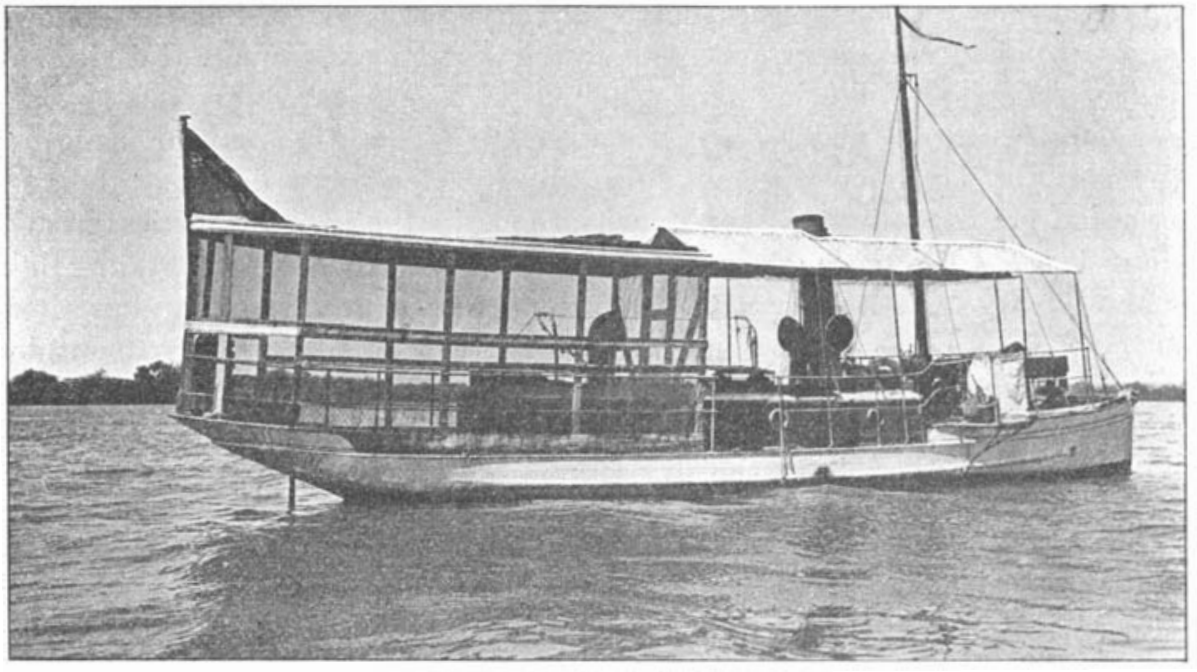

Fig. 13.-Surveying-launch "Rose"-to show effective mosquito-proofing.

Camp for Horses. - There are always a number of horses in Bathurst suffering from trypanosomiasis, and these are a source of danger to the uninfected horses. In addition to this, others are continually being brought down the river to Bathurst. It might be well therefore to have some sort of segregation stable erected in an open clearing about half a mile from Bathurst, where all infected and suspected cases could be segregated until pronounced free from trypanosomiasis. This method has been adopted elsewhere on the West Coast and has been found to reduce considerably the percentage of infected horses.in these places.

Instruction of Natives.-It is of the utmost importance that every endeavour should be made to instruct the natives in the connection between certain insects and disease in man and animals, and also as to the means, such as clearing, whereby the number of these insects may be reduced, with a consequent benefit both to themselves and their herds.

In conclusion, I wish to take this opportunity of expressing my indebtedness to His Excellency the Governor, Sir George Denton, K.C.M.G., for the interest he took in this investigation, and for the many facilities afforded me in carrying out the work expeditiously ; to Colonel C. W. O'Brien, C.M.G., for his many personal kindnesses and his untiring efforts to further the investigation; to Dr. T. Hood, the Senior Medical Officer, for his hospitality and his suggestions, based on a wide personal experience of the Colony; and also to the other Officers whom I met both socially and officially, through whose advice and help delay and loss of time were reduced to a minimum. 


\section{APPENDIX.}

\section{Hin'ts For COLlectors.}

In 1909 a pamphlet of "Instructions to Collectors" was prepared by the Entomological Research Committee and printed by the Colonial Office. Much of what follows is taken from this pamphlet, but several points have been amended and others added. The following hints refer more especially to bloodsucking insects and other arthropods, and are intended mainly for those who have had little or no experience in such work, but who wish to study the insect fauna of their district. The particulars here given emphasise, therefore, the points to which special attention should be paid, and present the more simple methods of collecting, preserving and despatehing for examination and identification.

\section{I.-APPARATUS AND GENERAL INSTRUCTIONS.}

The following is a list of the more important apparatus required for entomological collecting :-

Nets.-The most serviceable net is that known as the "kite net," the frame of which is in three pieces, the two side pieces being of wood and the top of curved cane; the rigidity of this frame permits of its being used also as a sweeping net. For winged insects the bag of the net may be of the ordinary green gauze; but this should be thoroughly soaked before use to get rid of the starch, otherwise the stiff material will damage all delicate insects ; tulle bags last much longer and are softer, but they are a good deal more expensive. It is well to have one or two spare net-bags. The $Y$ which holds the frame should be of brass, the parts being brazed together and not soldered, for solder is very apt to give.

Glass-bottomed pill-boxes.-These are indispensable for bringing home fragile insects or such as have easily detachable scales, e.g., moths, mosquitos, \&c. The most useful sizes are 1 inch, $1 \frac{1}{4}$ inch, $1 \frac{1}{2}$ inch and 2 inch diameter. Before using these a small hole should be pierced in the lid by means of a strong pin.

A brass chloroform-bottle.-Chloroform is especially useful when delicate insects, such as mosquitos, moths, \&c., have been brought home alive in the glass-bottomed boxes. The chloroform-bottle is constructed so that the liquid comes out in single drops. When it is desired to stupefy an insect contained in a glass-bottomed box before transferring it to the killing-bottle, apply the nozzle of the chloroform-bottle to the small hole in the lid, and sufficient liquid will come out to attain this object without damaging the insect.

Killing-bottles.-These should be made as follows : Into a wide-mouthed bottle put a layer of plaster of paris, from $\frac{1}{4}$ to $\frac{1}{2}$ an inch deep ; cover this with small lumps of cyanide of potassium; then add another quarter-inch layer of dry plaster, and cover the whole with a thin layer of plaster moistened to the consistency of cream. As the chemical union of water with the plaster generates heat, the bottle should be heated by placing it in warm water before the last layer is added; otherwise it is liable to crack. A large prune- or jam-jar is the best for home use, and smaller ones for the field. A large glass tube makes a 
very convenient pocket killing-bottle for smaller insects; this can now be obtained in a wooden case, and is consequently not so liable to be broken. If the bottle is used in the field it is essential that it should be three-parts filled with soft, loosely crumpled, absorbent paper (inferior newspaper serves quite well), for not only will this prevent the bottle from "sweating," but it will absorb the juices emitted by many insects, and will also prevent the insects from knocking about in the bottle. Delicate insects should not be put into the cyamide-bottle in the field, but should be taken home alive in the glass-bottomed boxes. In dry localities a killing-bottle will often become weak and ineffective - this may be remedied by pouring into it a few drops of vinegar or soda-water.

A few small camel's hair brushes (sizes Nos. 1 and 2), for catching and handling fleas and other emall insects.

Curved nickel-plated forceps, for handling pinned insects, \&c. Unpinned insects should be touched as little as possible with the fingers; they should be picked up either with the forceps or a camel's hair brush.

$A$ pocket lens.-This should magnify about 10 or 15 diameters; higher powers are not so generally useful.

Glass tubes for spirit specimens.-Tuhes of various sizes for this purpose are now procurable in wooden cases suitable for sending singly by post, while boxes containing 24 small tubes with a pipette and two camel's hair brushes for this work are now on the market. The corks should be of good quality and waxed to prevent evaporation of the spirit. The ordinary candle used in the tropics is quite suitable for this purpose. Such insects as fleas, bed-bugs, and ticks should always be preserved in spirit or formalin.

Store-buxes for pinned insects.-If the ordinary deal store-boxes are used, they should be given a good coat of varnish or enamel paint, otherwise they are apt to warp and split during the dry season in the tropics; the tops and bottoms should also be secured with screws, as they are liable to become detached by warping. For transmission by post, cigar-boxes lined with cork-carpet may be used; provided they have been first strengthened by nailing pieces of wood on the inside of the short sides (to support the ends of the lid), and by tacking crossstrips on the top and bottom.

Pins.-In general, it is unnecessary to pin insects for transmission to England, for unpinned specimens travel much more safely. But in the case of Diptera (two-winged flies), pinning is generally the more satisfactory method (for alternative methods, see special instructions for Diptera). The pins recommended are those manufactured by D. F. Tayler \& Co., the short No. 20 for all Diptera smaller than a house-fly, the short No. 10 for larger ones up to the size of a blue-bottle, and for still larger insects the long No. 16 may he used without staging.

Card discs.-The general employment of these is undesirable, they should only be used for smaller flies, especially those with long legs, such as mosquitos, \&c., a No. 16 pin being inserted near the centre as a support.

Paper envelopes for Diptera, Hymenoptera, \&c.-These are sometimes called "cushion envelopes," and should be made of fairly thin soft paper as follows: Take a rectangular but not a square piece of paper of suitable size, and write on 
it all particulars of capture. Then fold the paper as shown in the diagram (figs. 1 and 2). Place the forefinger of the right hand into the envelope thus made (fig. 2), and with the finger and thumb of the left hand firmly twist the apex so that a rigid pocket is formed (fig. 3). Place one insect in this, close the open portion by folding over the upper edge, and pass the thumb nail along the folded edge so as to secure the insect firmly (fig. 4). If the paper is too stiff, the cushion will be too rigid and the insect will shake about inside it, with probable damage to the legs and antennae.
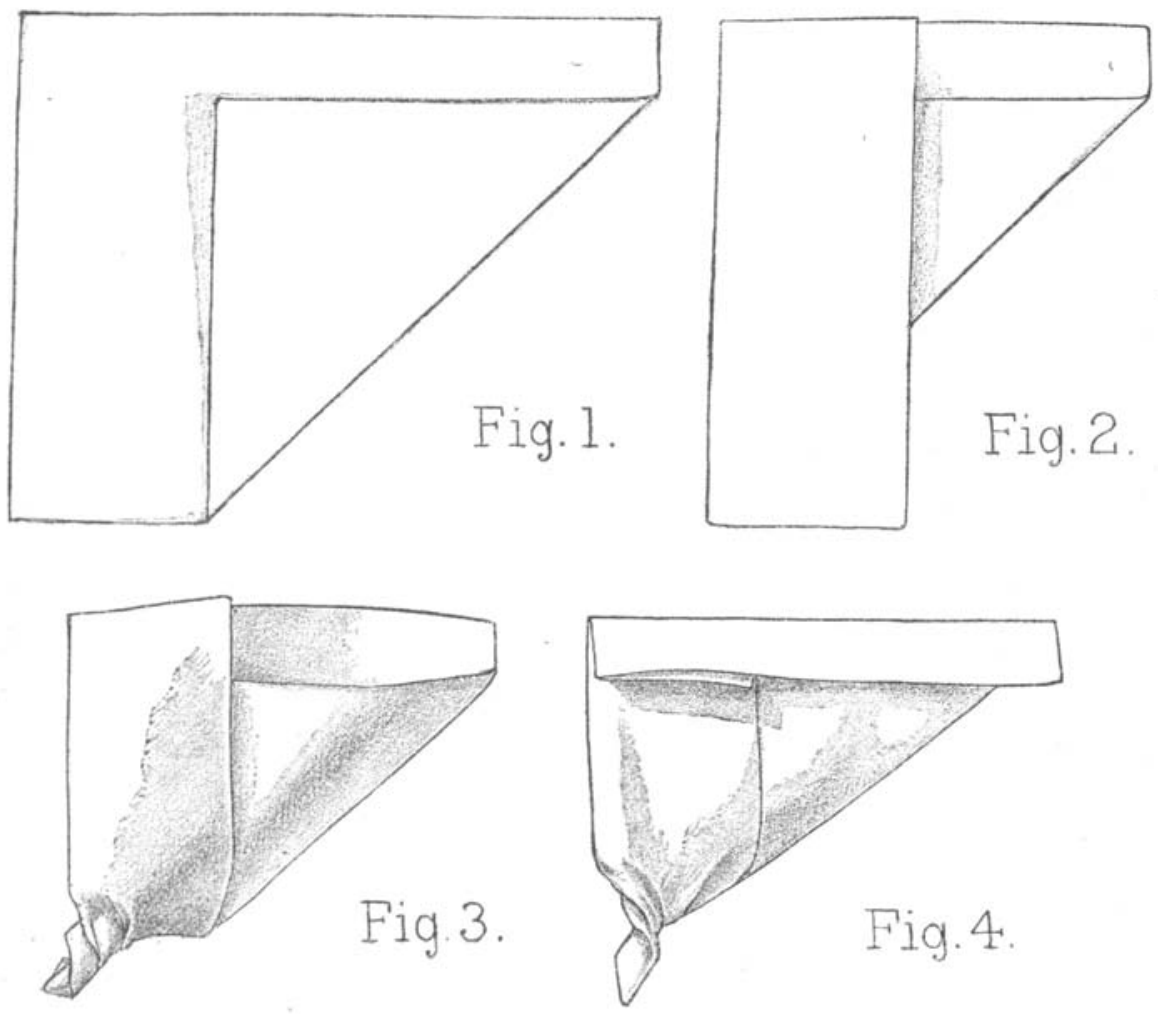

Diagrams to illustrate the construction of "Cushion " envelopes.

Strips of cork-carpet and peat for pinning operations, and for improvising storehoxes.

Chip-boxes or cardboard-boxes are useful for specimens in envelopes.

La BELS. - It is impossible to insist too strongly upon the immense imporfance of giving full data for every specimen captured. The following points should be mentioned on every label:-(1.) Name of locality; in the case of native villages, farms, and so forth, the compass-bearing and approximate distance to the nearest well-known town, river, mountain, \&c., should be stated; (2) altitude; (3) dateday, month, and year-thus, 8. V. 09 ; (4) collector's name ; (5) any brief note of interest, such as the name of the fool-plant ; the name of the host, in the case of a parasite, \&c. Louger notes on habits, range, seasonal oceurrence, economic 
significance, \&c., should be kept in a note-book, under a number corresponding with a number on the specimen. In the case of pinned insects, where the brief data are precisely similar for a long series of specimens, a small square of paper of a particular colour may be attached to each insect, and labels giving the data need only be attached to one or two of them. Whenever insects are taken paired, this should be carefully noted, and they should be labelled respectively, "A-in cop. with $A^{1}$," and " $A^{1}$-in cop. with $A . "$

Preservation.-Mould may be effectually prevented by rubbing the inside of the box in which insects are pinned with a bit of sponge soaked in ordinary medical (beechwood) creosote, until the cork lining shows through the paper. As an additional precaution, a small quantity of naphthalin should be melted in a testtube, or iron spoon, and poured into a corner of the box, to which it will firmly adhere. The latter method may also be adopted in the case of boxes containing insects packed in papers or in sawdust, a few drops of creosote being first sprinkled on the bottom of the box, and a few more drops on the lid when it has been filled. Ants are often a serious pest to the entomologist in the tropics. They will not enter boxes which have been prepared as above, but it is advisible to isolate the tables on which insects are kept by placing the legs in saucers or shallow tins, which are then thickly sprinkled with Keating's Powder or filled with kerosene. In no circumstances should water be used as this almost invariably serves as a place for mosquitos to deposit their eggs. Creosote must never be allowed to touch the specimens directly, and in all cases it must be used very sparingly, otherwise it is liable to discolour the insects permanently.

Bionomics.-Any information with regard to the natural habits of noxious insects is certain to be of value, however trivial it may appear to the observer. For example, any of the following points may be usefully noted ; peculiarities of local distribution, seasons of appearance and disappearance, relative abundance in different years, times of feeding, nature of food, methods and times of egg-laying, food and habits of larvae, \&c., \&c. Further, good series of any injurious insect should be sent from every locality visited, even though they may be only a few miles apart ; for only thus can a proper survey of its entire range be made. A knowledge of the egg, larva, and pupa is often of considerable importance, and whenever insects are being reared specimens of each stage should be preserved in spirit.

In the case of insects preserved in spirit it is desirable to keep them for a day or two in a weak solution of 35 or 40 per cent. before transferring them to the final solution of 65 or 70 per cent.

Where alcohol of known strength cannot be obtained, any spirituous liquid may be used provided it possesses the requisite strength. Any spirit which takes fire immediately on the application of a light, without having been previously warmed, is strong enough to be used for the preservation of animals.

Insects intended for anatomical examination must be fixed by heat, as their chitinous envelope is penetrated so slowly by alcohol that, if this be not done, they decompose before the preservative can reach them. It is sufficient to bring them to boiling temperature in a test tube of water; but for delicate histological 
work it is better to boil in a mixture of equal parts of 90 per cent. alcohol (ordinary rectified spirit) and an aqueous solution ( 1 in $\tilde{500}$ ) of perchloride of mercury. Even protozoal parasites are well preserved by this method. When fixed, preserve in 90 per cent. alcohol. Methylated spirit should not be used, as its acidity and other impurities may lead to embarrassment in the use of aniline stains.

The corks of tubes containing alcohol should be covered with paraffin wax to prevent leakage. In hot climates the wax of a stearine candle will be found more satisfactory on account of its higher melting point.

Collectors who desire to assist the Committee in furthering the organised study of African economic entomology should send their material to-

\section{The Scientific Secretary, Entomological Research Committee, British Museum (Natural History), Cromwell Road, London, S.W.}

\section{II.-INSTRUCTIONS FOR COLLECTING AND PRESERVING FLEAS.}

Collecting.-Fleas are found on both birds and mammals, but in order to secure them the hosts must be examined when alive or just freshly killed; for fleas leave their host as soon as it gets cold.

Should the host be small, immediately after death it may be placed in a cyanide bottle, or in a small box or tin containing a few drops of chloroform, benzine, or ammonia. The tleas, after a few minutes, will be found dead at the bottom of the receptacle or among the hairs and feathers. They can then be easily picked up with a small moistened paint-brush and transferred at once to the alcohol in the collecting tubes.

In the case of large mammals and birds the tleas must be searched for by turning back the hair or feathers; and they may be killed by touching them with a brush moistened with spirit, benzine, or chloroform.

The following is a convenient plan for securing fleas found on birds:-Take a bird's nest immediately the young have left it and place it in a box, preferably one lined with white paper and with a glass top. A certain number of fleas will probably emerge at once from it; but there will be many larvae and pupae still in the nest. These may be reared simply by slightly moistening the nest from time to time, and mature fleas will frequently keep on emerging for six or eight weeks after the nest has been taken. The live fleas can be taken off the sides and top of the box with a camel's hair brush dipped in chloroform or benzine.

If it is impracticable to breed the fleas in this manner, the nest may be shaken up in a linen or paper bag containing several drops of chloroform or ammonia. After a few minutes the contents should be spread out on a white cloth or paper, and the dead insects can be picked up with a moist brush. Nests of moles, rodents, \&c., can be treated in the same way. 
It is important that the name of the host should be accurately determined, and therefore, wherever possible, skins of the smaller animals should be sent home for identification. Such skins would be returned, if desired. In the case of small mammals, the skulls should always be sent with the skins.

"Jiggers" or "chigoes" are highly specialised fleas, the females of which burrow beneath the skin of their hosts, on the more naked portions. They are to be found on many kinds of mammals and birds ; and sometimes they present the appearance of small warts on the skin. For collecting purposes, they should not be pulled out, but, wherever practicable, the infected portion of the skin should be cut out and preserved in spirit; or the insects may be killed in situ with chloroform and then removed very gently.

Preserving.-Fleas should always be preserved in alcohol ; 50 per cent. rectified spirit is found to be the most satisfactory strength. Each tube should contain the fleas from one host only, and many specimens should be sent, as frequently there are several species of flea on one animal.

LABELling.- In every tube a label should be inserted giving the locality, altitude, date, collector's name and name of the host; where the name of the lost is unknown, a number should be given corresponding with one attached to the skin. Labels should be written very clearly in soft pencil or Indian ink.

Packrng.-When packing tubes for transmission to England, a piece of soft crumpled paper should be inserted in each, in order to prevent the contents shaking about in transit. Care should also be taken to fill all tubes completely with alcohol before they are despatched, so as to leave as small an air bubble as possible. Reject all corks that appear defective and see that each cork is well rammed home and sealed with wax from a stearine candle. Then place the tubes in the receptacles provided for them, and carefully pack these in a covering box or tin.

\section{III.-INSTRUCTIONS FOR COLLECTING TICKS.}

Habitats.-All the domesticated and a large number of wild mammals are subject to the attacks of these pests. Some species also are to be found on birds (the head being the favourite point of attack), while others are peculiar to reptiles and batrachians. Several kinds attack man, especially in the larval stages; but the most important human ticks belong to the genus Ornithodoros (family Argasidae). These are not permanent parasites, and must be looked for in native huts, rest-places, \&c. ; they bite only at night, and during the day hide themselves in the dust on the ground, in the mud-cracks on the floor and walls, and also in the thatch. Fowls are subject to the attacks of a similar tick (Argas persicus), which may be found under similar conditions in fowl-houses.

Collecring.-Ticks vary greatly in size, not only in the different species, but also in the various stages of development. Examples of all sizes found on a host should therefore be collected and a liberal supply of each should be sent. The males of many species are relatively very small compared with the females, and require to be carefully searched for ; they may often be found beneath the gorged females. Males of Licodidae may be recognised by having the whole back covered with a hard shield. 
If ticks are roughly removed, an important part-the "false head"一will be left behind, embedded in the host's skin, and the specimen spoiled. They may best be removed with a flat-nosed forceps, care being taken to grip the "false liead" as close to the skin of the host as possible. If the creatures will not come away without breaking, they may be induced to let go by touching them with a brush or finger dipped in any oil. Headless examples are useless for study. The minute larvae (" seed ticks") may be removed with the blade of a knife and are best scraped direct into the tube.

All parasites from one species of animal from one locality and taken on the same day may be placed together in the same tube, but care must be taken not to mix the parasites of different animals (e.g., sheep and cattle) though from the same place. Especially is it important to keep parasites from different localities separate.

Killing.-To kill ticks it is necessary only to drop them direct into the preservative. If the species are very active, they may be touched with a camel's hair brush moistened with chloroform or ammonia. When conditions are favourable, a good way to kill ticks is to drop them into 25 per cent. alcohol, to which 2 or 3 drops of ether have been added. The ticks then die with their limbs extended, and can afterwards be transferred to the proper preservative.

Preservatives.- It is preferable that ticks should always be preserved in liquids. Either of the following may be used : (a) 65 per cent. rectified spirit; if this is not procurable, undiluted whisky or gin may be substituted, though much less satisfactory ; (b) 3 per cent. solution of formalin; care must be taken that the solution is not made stronger, as it would then render the specimens too hard and brittle. When plenty of material is available, both methods of preservation should be used.

LABELLING.- Write legibly on a slip of good white paper : (1) name of host, or a number corresponding with one on the skin of host, if the latter is sent home for determination; (2) locality in full, not omitting the Colony or Protectorate, and in the case of farms or native villages, giving the approximate distance from the nearest well-known township, mountain, river, \&c.; (3) altitude ; (4) full date; (5) name of collector. Writing is best done with a fairly soft black graphite pencil. The label thus prepared should be placed inside the tube with the specimens. If ordinary writing ink is used the label must be attached to the outside of the tube. When it is desired to send fuller notes concerning certain species, take a piece of soft tissue paper, write a number on it in pencil, then fold up several specimens of one species in it; the paper should be folded over a good many times, and its final size should be such that it fits tightly into the tube and cannot become unfolded in transit. Under a similar number an account can be sent home of the habits, \&c., of the species. In the case of distinctively coloured species, the colours should be noted during life and duly recorded. Any notes on habits, distribution, frequency, \&c., would be greatly appreciated.

Packing.- See that the corks of the tubes are well rammed home. Reject all defective corks. When the tubes are being finally closed, a lightly crumpled piece of soft paper may be inserted to prevent the specimens moving about too much. The tubes should also be quite filled up with the preservative. A large 
air-bublele may be avoided by pressing the cork to one side when pushing it home. When the tube has been closed, the cork and the edges of the tube should be covered with melted wax to check leakage; the wax from an ordinary stearine (or mining) candle will be found most satisfactory. The tubes must be returned in the wooden cases provided, and these should be carefully packed in a covering box or tin.

\section{IV -INSTRUCTIONS FOR COLLECTING AND PRESERVING BED-BUGS (CIMICIDAE).}

Collecting.-When a house in the tropics is found to contain bugs, the tops of all the mosquito-nets should at once be examined, as that is a favourite resort for these insects. Bugs may also be obtained, when troublesome, by spreading a broad ring of pyrethrum powder right round the lower sheet or blanket upon which the sleeper lies; every bug that crosses this to attack him will be found more or less disabled in the morning.

Where fowls are kept, the nesting-boxes should be periodically examined, for these will often be found simply teeming with bugs; and this should always be suspected when the fowls are found to be laying away from their boxes. Bugs are also to be found in some birds' nests, especially those of swallows. Other species specially attack bats; these are mostly' to be found in the cracks and crannies about the places where bats roost, and can be driven out by the use of ammonia or tobacco smoke; sometimes the insects are found attached to the membrane of the bat's wings, which should always be carefully examined.

It is quite probable that on fuller investigation different species of bugs will be found frequenting the lairs of many other animals.

KILLING.--These insects may either be killed in the cyanide bottle or dropped directly into the preserving fluid.

Preserving.-Bed-bugs should never be preserved dry ; they should be kept in 60 per cent. spirit or 3 per cent. formalin. As far as possible, each tube should contain the bugs from only a single host.

Labelling and Packing.-See the instructions given for ticks.

\section{V.-DIPTERA (TWO-WINGED FLIES).}

\section{INSTRUCTIONS FOR COLLECTING MOSQUITOS, AND OTHER SMALL OR DELICATE FLIES.}

Collecting.- Many species of mosquitos may be obtained during the day in shady woods or forests ; others prefer open, swampy ground, and can best be secured in numbers just after sunset; others again can be most conveniently collected in houses. When caught with a net in the open the insects should be brought home alive in glass-bottomed pill-boxes. In houses, it will be found that most of the mosquitos fly to the windows at dusk, and they may then be caught in the following way: Take a pill-box and firmly fix across the bottom a strip of blotting-paper, on which place a drop or two of chloroform or ammonia; the box should then be put over a mosquito on the window; in a few seconds the insect will be partly stupefied and can then be transferred at once to the cyanide bottle, the box being immediately placed over another insect, and so on; by this means a good series can often be obtained with 
comparatively little trouble. These insects often collect in some numbers during the day on the thatch inside native huts, and many may be captured with a few sweeps of the net; special attention should also be given to those species which attack domesticated animals. Mosquitos may be bred quite easily from larvae, and this method of collecting should be adopted whenever practicable.

The minute insects known as "sand flies" (Simulium, Phlebotomus and Culicoides) should be carefully collected. Simulium, so far as is at present known, breeds in shallow running streams. The larrae attach themselves to the stems of plants and stones; when matured, the flies are readily bred by placing the larvae in situ on portions of the plant or on stones in a glass vessel, which should be covered over with a piece of rubber sheeting. Water must not be added or the larvae will die off rapidly. The plants or stones, however, must be kept moist. Phlebotomus may be looked for in latrines and damp shady places. Culicoides often swarm along rivers and elsewhere; the members of this genus are all minute, and examples should be preserved in alcohol as well as in a dry condition.

Kiling.- When the mosquitos, \&c., have been brought home alive, they may be killed by the method described nnder the heading "Brass chloroformbottle." Ammonia may be used instead of chloroform, but on no account should they be shaken into the killing bottle as they are thus inevitably damaged. The boxes should be afterwards left open some time before being used again for live insects.

Preserving.-For all general purposes it is desirable that mosquitos should be preserved dry. Specimens to be identified must on no account be placed in spirit. Mosquitos must be dealt with as soon as possible after death, for they very rapidly become dry and stiff, in which state they cannot be touched without breaking and are therefore useless for transmission.

The insects may be sent home either pinned or unpinned. If pinned, the following process should be adopted. Cut a small piece of paper of sufficient size to write on it all data connected with the specimen to be pinned, as follows : name of locality, including altitude if necessary ; date-day, month, year-thus, 9. XI. 98 ; collector's name; any remarks of interest, e.g., "Most troublesome species in district," "Abundant only in open swamps," "Uncommon," \&c. Then take one of the fine No. 20 pins and thrust it through the middle of the mosquito's thorax on the upper side, gently pushing the insect two-thirds of the way up the pin and taking great care not to break off the legs; this may conveniently be effected by stretching a corner of a handkerchief between the fingers and then gently pushing the pin through the fabric.

In the case of mosquitos, a good number of specimens of each species (but not more than half) should be pinned through the side of the thorax instead of from above; while the majority (say two-thirds) of the midges and sand flies should be pinned in this manner. Then place the paper on a piece of cork or peat with the writing downwards, seize the pin with the forceps (below the specimen) and thrust it through the paper, and finally, with a pin, arrange the wings so that they project at an angle from the body and dispose the legs symmetrically. This latter operation must be performed very gently, and care must be taken 
that hairs and scales are not rubbed off ; as the tissues contract in drying, the legs and wings are very apt to get pulled out of place, and to correct this, the specimens should be examined once or twice during the next day or two. If precisely the same data apply to a number of specimens, it will be necessary to label only two or three, provided that a small label bearing the same number be attached to every specimen; or else this may be indicated by drawing a pencil line round the whole group on the bottom of the box in which they are ultimately pinned.

Packing.-Pinned specimens,-The inside of the box into which the insects are to be pinned should first be rubbed with a piece of sponge, or swab of cottonwool, soaked in a saturated solution of naphthalin in chloroform, mixed with an equal quantity of medical (beechwood) creosote ; the mixture being applied until the cork-lining shows through the paper. This process will prevent nould and keep out destructive insects. The specimens should then be very firmly pinned into the box, a sheet of newspaper or other soft paper should be placed over the side containing the insects with the edges projecting so that on closing the lid it is held firmly in position. This minimises the risk of injury in the event of any of the specimens becoming loose in transit. The box containing the pinned insects should then be well wrapped in cotton-wool, shavings or moss, and enclosed in a covering wooden or tin box.

Unpinned specimens.-These should be packed in the following manner, immediately after being killed. Take a very small piece of cotton-wool, tease it out into a light web-like mass, put this into a pill-box and so arrange it that it fills about two-thirds of the receptacle. Place the mosquitos or other small flies upon the wool, care being taken to distribute them evenly, and not too closely, over its surface. A very thin web-like layer may then be placed over the insects, but there must be no pressure upon them, tight packing must be strictly avoided, and unravelled plugs of wool must not be used. Dry rigid specimens cannot be packed in this way. There must be only one layer of insects in each box. A single drop of medical creosote should be placed on the inside of the lid of the pill-box; if too much creosote be used, the specimens will be permanently discoloured. The data should be written, as above, on the outside of the box. The pill-boxes may then be carefully packed in a strong larger box for transmission. When sufficient specimens are available, it is advisable that both methods of packing should be used, and in the case of biting flies, some of each kind should also be preserved in spirit.

\section{VA.-INSTRUCTIONS FOR COLLECTING LARGER DIPTERA (TWO-WINGED FLIES).}

Collecting. - In general, flies should be brought home alive in the glasshottomed pill-boxes; but when large numbers are being caught this is sometimes impracticable, and a cyanide-bottle containing pieces of soft crumpled paper should be carried in the field. It is worth noting that Diptera may often be captured in quantities by sweeping in open marshy ground or in damp shady places. When a good many have thus been secured in the net, it should be waved rapidly backwards and forwards with one hand, then with the other hand the 
bag of the net should be seized near the bottom so as to imprison the flies in a small space; this portion can then be placed bodily into the killing-bottle for a minute or so, and when the insects cease to move they can all be transferred to the bottle.

The flies which are most urgently required are those which suck the blood of men and animals, and of these long series should be sent from every different locality visited. Tabanidae, Stomoxys, and tsetse-flies ( $G l o s \operatorname{sina}$ ) may often be captured while attacking man and other mammals; and it should be remembered that freshly-killed animals are often as attractive, if not more so, than living ones.

Killing.-Flies brought home alive may be killed by the method recommended for mosquitos.

Preserving.-For general purposes these insects should be preserved $d r y$, cither pinned or in papers.

Pinned Specimens.-For insects not larger than a blue-bottle a No. 10 pin should be used, and they should be treated in exactly the same manner as mosquitos. In the case of larger flies, they may be pinned with the long No. 16 pins. The insect should be pushed up the pin for at least two-thirds of its length, and a card, on which all the data have been written, should be run up the pin close beneath the insect, so as to serve as a support for its legs.

Unpinned Specimens.-Prepare a number of rectangular pieces of fairly thin soft paper ; $2 \times 2 \frac{1}{2}$ inches will be the most generally useful size, but $2 \frac{1}{4} \times 3$ inches would be needed for the largest Diptera. Take one of these papers and write on it all the particulars of capture, including the locality, date, name of collector, \&c. Make this into a "cushion" envelope as described and figured on page 229, and pack only one insect in each. Never use gum to fasten the edge of the envelopes.

Packing.-Dinned Insects.- These should be treated in precisely the same manner as mosquitos. In the case of large insects, special care must be taken that the pins are firmly driven into the bottom of the box as far as they will go. In doing this never hold the pin above the insect, but always belovo it.

Insects in Papers.-For packing these, take a small tin or wooden box, pour a few drops of medical creosote and also a spoonful of melted naphthaline into it to prevent mould. Cover the bottom with a sheet of paper, then carefully put in the envelopes in such a way as to minimise the pressure on the insects, and replace the lid as soon as possible to prevent the evaporation of the creosote. When the box is full, place a layer of teased-out cotton-wool on the top of the envelopes, using just sufficient to prevent them from moving about without unduly pressing the specimens. Carefully pack the box in a covering box, and dispatch it as soon after it is filled as possible. If the specimens have been kept for six weeks or so before posting, put a few more drops of creosote on the cotton-wool covering the envelopes. On no account must an excess of creosote be used or it will discolour the insects. If medical creosote or other preventive of mould is not procurable, the insects must be kept in wooden boxes only and as free from damp as possible. In very moist climates it mas be found necessary to expose such specimens near a fire from time to time, or to place them in the sun, care being taken not to allow ants or other destructive insects to gain access to them. 


\section{VI.-TSETSE-FLIES.}

\section{Some of the Points on which Observations are wanted.}

1. Iocality.-Name of colony and nearest station, river, lake, \&c. It is not always possible in England to identify native villages.

2. Where caught.-On road, at ford, in village, close to village, far from human habitation, on railway, \&c.

3. Altitude, if known.

4. Time of day.-If caught at night, ? moonlight.

5. Nature of country.-River bank, grassy plain, dense forest, thorny scrub, \&c.

6. Presence or absence of water.

7. Dry or wet season.-State whether the grass or scrub is burned in the dry season.

8. Presence of more than one species.-This is casily orerlooked, as some of the species are very similar to one another.

9. Number's of $f y$.-Half-a-dozen, numerons, very numerous, swarms, \&c.

10. Ratio of the sexes.-Males usually outnumber females.

11. Do the flies bite through clothes?

12. Have you observed any bird or insect preying on the flics :

13. Do the flies go to the water to drink?

14. Are cattle, sheep, goats, or horses kept in the fly region?

15. Presence or absence of sleeping sickness.

Observations carried on month after month at one spot are of more value than spasmodic research in diverse districts.

\section{VII.-INSTRUCTIONS FOR COLLECTING LICE.}

\section{I.-Sucking Lice (ANOPLURA).}

The true or sucking lice are placed by most systematists near the RHYNCHOTA (HEMiptera) and the Thysanoptera. Their mouth organs partly consist of very thin, long, piercing-bristles. These are, however, very difficult to see on account of their extreme thinness and lack of all colour. By means of these organs the ANOPLORA can be distinguished from the so-called biting lice, Maldophaga, which live on the hair or feathers of their hosts and whose mouth parts are adapted to biting as opposed to sucking.

The Axoplura can be found on all mammals of all sizes. In most cases they can be combed out from the hair of their hosts with a common tooth-comb. In the case of mammals with very slight pelage it is better to search the skin for these parasites, which can be killed by dropping a few drops of chloroform on them, and can then be removed with a small brush or a pair of forceps. As a rule, only a few individuals of any one species of mammal are infested with lice, but in these cases the insects generally occur" in large numbers and especially so if the animal is young or weak. It is very advisable to examine a large number of individuals of any one host, cspecially of those from which no lice are as yet recorded. Lice are especially desired from all carnivora, such as cats, carnivorous whales, \&c. Aquatic animals such as seals, are often 
infested with lice in the neighbourhood of the nose and mouth, even when there are none to be found on other parts of the body. Large quantities of each species should be collected, and also larva in all their stages. The eggs are also of very great importance. They are always laid on the hairs, and the hairs should be cut off with the eggs adhering to them. The parasites from each individual host should always be kept separate from any others, whether these are collected on the same species of animal or a different one, and it should be noted that as the parasites leave their host as soon as it gets cold, there should be no loss of time in examining the dead animal. Lice can frequently be collected from mammals in captivity in zoological gardens, especially when. they are freshly captured. For preserving lice the following method is recommended. The parasites and their eggs and larvæ have simply to be placed in a small glass tube filled with alcohol. A label should then be inserted giving the name of the host, the date, and locality. When recording data the following points are essential :-(1) Exact locality and its altitude ; (2) date ; (3) the name of the host, and if this is unknown, a number corresponding to numbered specimens of the host ; (4) the age and sex of the host; (5) condition of the host, i.e., whether weak or emaciated, or in good condition; (6) position on the body of the host where lice were chiefly found and also position of the eggs ; (7) collector's name.

\section{II.-Biting Lice (MALLOPHAGA).}

The biting lice or Mallorhaga, which live on hair and feathers, are in no way related to the previously mentioned Anoplura, but are Neuroptera allied to the Copeognatha (Psocida). They undoubtedly bear a striking superficial resemblance to the ANOPLURA, especially as they possess tarsi with strongly developed claws, and the thorax and abdomen are strongly compressed dorso-ventrally, but notwithstanding all these characters they are in no way related.

The biting lice living on mammals (sometimes called hair lice) occur, like the sucking lice, on all mammals, and the eggs of these parasites, which are very important and have a characteristic shape for each species, should be carefully collected. The feather lice or biting lice found on birds cannot be combed out from their hosts, which is the method suggested for the previously-mentioned insects. These must be taken off from the host with a brush previously moistened with chloroform or benzine. On one species of bird quite a number of lice of different genera and species can often be found. The eggs of feather lice are generally laid on the under surface of the feathers and frequently on the base of the feather, and as they are usually deposited in little groups they can easily be cut off and preserved. Collectors should note that some species of Mallophaga, like the Aroplula, often leave their host as soon as it gets cold. The method of preservation for Mallophaga is the same as that recommended for the Anopluka. 


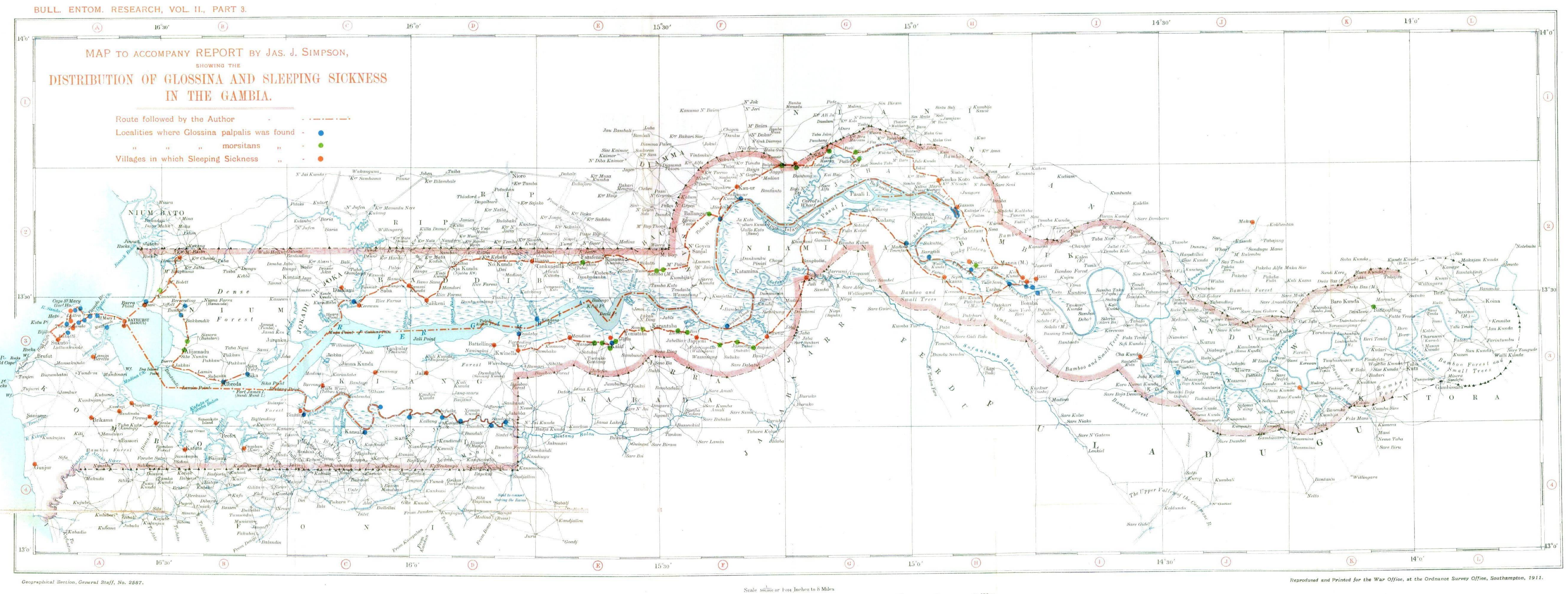

